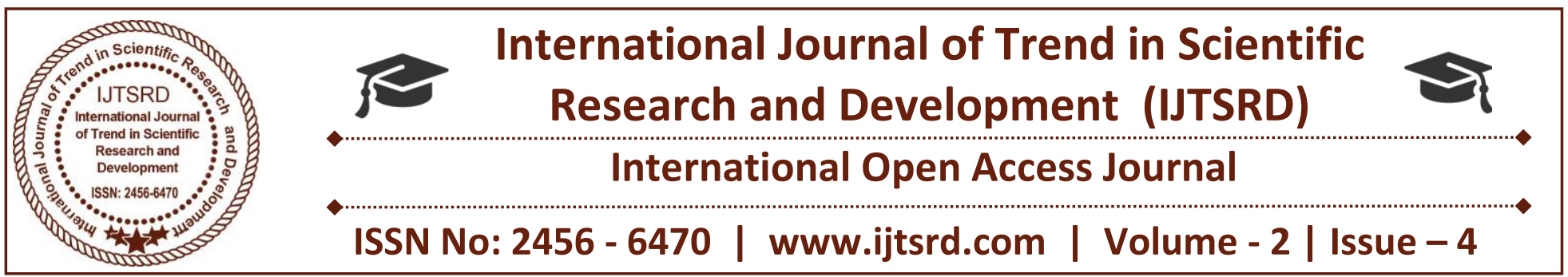

\title{
Extraction and Analysis of Pyrolysed Oil Derived From HDPE
}

\author{
T. Kathiravan, S. Mohamed Nasrulla, G. Saravanan \\ Assistant Professor, Department of Mechanical Engineering, \\ PSNA College of Engineering and Technology, Dindigul, Tamil Nadu, India
}

\section{ABSTRACT}

The present study summaries the extraction and analysis of pyrolysed oil derived from waste plastic. The current rate of economic growth is unsustainable without saving of fossil fuels like crude oil, natural gas, coal etc. There has always been an increase in demand for fossil fuels while at the same time a depletion in its amount. Development and modernization have brought about a huge increase in the production of all kinds of commodities using plastics which indirectly generates waste./ Plastics have wide range of applications due to versatility and relatively low cost. This project focuses on the importance and implementation of Waste to Energy technology by deriving pyrolysed oil from plastic. The plastic opted for experimentation is High Density Polyethylene due to its properties favoring the process of Pyrolysis. Pyrolysis is the process of thermal degradation of plastic in the absence of oxygen. An experimental setup in order to accomplish pyrolysis was fabricated and thus, the raw pyrolysis oil was extracted. The raw fuel derived was vacuum distilled to obtain the clear pyrolysed oil, whose analysis conducted in a Computer Integrated IC Engine test rig. The performance, efficiency and emission test of the distilled pyrolysed oil was experimentally calculated by blending with diesel at different blend ratios.

\section{INTRODUCTION}

Waste-to-energy (WtE) or energy-from-waste (EfW) is the process of generating energy in the form of electricity and/or heat from the primary treatment of waste. WtE is a form of energy recovery. Most WtE processes produce electricity and/or heat directly through combustion, or produce a combustible fuel commodity, such as methane, methanol, ethanol or synthetic fuels. During the 2001-2007 period, the waste-to-energy capacity increased by about four million/metric tons per year. Japan and China each built several plants based on direct smelting or on fluidized bed combustion of solid waste. In China there are about 434 waste-to-energy plants in early 2016. Japan is the largest user in thermal treatment of municipal solid waste in the world, with 40 million tons. Some of the newest plants use stoker technology and others use the advanced oxygen enrichment technology.

Pyrolysis of Waste Plastic To Produce Fuel Oil Mohammed M Garb Allah-Studied thermal pyrolysis of plastic waste leads to the production of fuel oil, valuable resource recovery and reduction of waste problem. It has been shown that the conversion at lower temperature in the presence of catalyst into liquid is a feasible process. An important difference is that the oil obtained relatively with greater volume and low boiling range in the presence of catalyst as compared to pyrolysis in the absence of catalyst. Pyrolysis of HDPE and Ldpe Vijaykumar Bdescribes the process of converting plastic waste into fuel. Basics of plastics and classification of plastics like HDPE and LDPE and their examples and uses. Pyrolysis process where the waste plastic converts into liquid fuel. The steps involved in the process. Description about the components for the experiment. The purification of liquid fuel is by distillation process. Thermal Liquefaction Of Waste Plastic Dr. H.H.Shinde-Studied conversion of waste plastic into a resource. Thermal liquefaction in presence of hydrogen gas can produce more liquefied hydrogen than nitrogen based system. Catalytic cracking 
followed by thermal liquefaction can facilitate effective conversion of waste plastic into liquid fuel. Thermo catalytic process is having potential or effective conversion of waste plastic to fuel. Synthesis of Pyrolysed Oil from Plastic Kanika Mathur-describes an attempt to use waste plastic to synthesize potential fuel called pyrolysis oil. Since the process used in order to obtain the oil is pyrolysis. The obtained oil from different grades of waste plastic is analysed so as to 696validate its use as fuel. Vacuum Distillation of Pyrolysed Oil Songhai Wiriyoumpaiwong-In this paper, distillation of pyrolysis oil obtained from fast pyrolysis of plastic wastes. Fractional distillation is commonly used to separate the petroleum oils. The distillation had a lighter colour than the pyro lytic oil samples. The distillation was light yellowish in colour. The distilled product from the pyro lytic oil from plastic waste has potential to be used as gasoline replacement fuel. Catalytic Pyrolysis of HDPE Yb Sonawane-In this paper, onsite conversion of thermoplastic waste into fuel by catalytic pyrolysis. Pyrolysis of high density polyethylene waste in the form of carry bags was carried out in an in-house fabricated glass reactor. The maximum temperature in reactor was kept about $550^{\circ} \mathrm{c}$. Reaction was carried out with and without using catalysts. It was found that time required for completion of the pyrolysis process was $3.5 \mathrm{hrs}$ without catalyst and $2.5 \mathrm{hrs}$ with catalyst. Design And Fabrication Of Pyrolysis Reactor Manjunath SStudied pyrolysis of waste plastic into fuel. Design and fabrication of a pyrolysis reactor caco3 can be used as a catalyst to crack LDPE plastic. The waste LDPE plastic was chosen because of its low melting point of $98-115^{\circ} \mathrm{c}$. The fuel obtained was subjected to atmospheric distillation. Degradation of Plastic in Glass Reactor Thallada Bhaskar-In this paper, the degradation process is carried out in a glass reactor. The caco3 sorbent completely removed the chlorine content and produced halogen free liquid products. The presence of water in the plastic mixture did not affect the characteristics of liquid products. PVC produces hydrochloric acid which leads to formation of halogenated hydrocarbons in liquid products. So there are not suitable to use as a fuel oil in refinery. Modelling of Batch Gasification Pyrolysis Reactor P. Baggio-In this paper experimental and modelling analysis of a batch gasification/pyrolysis reactor. An experiment bench scale apparatus for biomass gasification and pyrolysis has been designed.

\section{SELECTION OF MATERIAL FOR PYROLYSIS}

HDPE is known for its large strength to density ratio. The density of HDPE can range from 0.93 to 0.97 $\mathrm{g} / \mathrm{cm} 3$ or $970 \mathrm{~kg} / \mathrm{m} 3$. Although the density of HDPE is only marginally higher than that of low-density polyethylene, HDPE has little branching, giving it stronger intermolecular forces and tensile strength than LDPE. The difference in strength exceeds the difference in density, giving HDPE a higher specific strength. It is also harder and more opaque and can withstand somewhat higher temperatures $\left(120{ }^{\circ} \mathrm{C} /\right.$ $248{ }^{\circ} \mathrm{F}$ for short periods). High-density polyethylene, unlike polypropylene, cannot withstand normally required autoclaving conditions. The lack of branching is ensured by an appropriate choice of catalyst (e.g., Ziegler-Natta catalysts) and reaction conditions High-density polyethylene, unlike polypropylene, cannot withstand normally required autoclaving conditions. The lack of branching is ensured by an appropriate choice of catalyst (e.g., Ziegler-Natta catalysts) and reaction conditions. The physical properties of HDPE can vary depending on the moulding process that is used to manufacture a specific sample; to some degree a determining factor are the international standardized testing methods employed to identify these properties for a specific process. For example, in Rotational Moulding, to identify the environmental stress crack resistance of a sample the Notched Constant Tensile Load Test (NCTL) is put to use.

Owing to these desirable properties, pipes constructed out of HDPE are ideally applicable for potable water, and waste water (storm and sewage) force mains across multiple municipalities, namely Toronto Water.

\subsection{APPLICATIONS OF HDPE}

HDPE is used for cell liners in subtitle D sanitary landfills, wherein large sheets of HDPE are either extrusion or wedge welded to form a homogeneous chemical-Resistant barrier, with the intention of preventing the pollution of soil and groundwater by the liquid constituents of solid waste. HDPE is preferred by the pyrotechnics trade for mortars over steel or PVC tubes, being more durable and safer. HDPE tends to rip or tear in a malfunction instead of shattering and becoming shrapnel like the other materials. Milk jugs and other hollow goods manufactured through blow moulding are the most 
important application area for HDPE, accounting for one-third of worldwide production, or more than 8 million tonnes.
From the below tables it is clear that it's HDPE which has the highest tensile strength. This energy could be released while pyrolysis and the oil would have high calorific value.

Table 2.1 Physical properties of various plastics

\begin{tabular}{|c|c|c|c|c|}
\hline Name & Density $\left(\mathrm{g} / \mathrm{cm}^{3}\right)$ & $\begin{array}{l}\text { Melting } \\
\text { Point } \\
(\mathrm{C})\end{array}$ & $\begin{array}{l}\text { Tensile } \\
\text { Strength (PSI) }\end{array}$ & $\begin{array}{l}\text { Water } \\
\text { Absorption (\%) }\end{array}$ \\
\hline HDPE & 0.95 & 130 & 4500 & 0.01 \\
\hline LDPE & 0.92 & 120 & 1700 & 0.01 \\
\hline PP & 0.94 & 160 & 5000 & $0.01-0.03$ \\
\hline PS & 1.05 & 240 & $6671-8702$ & $0.03-0.1$ \\
\hline
\end{tabular}

and heated by means of electrical energy. The yield

Also it is clear that the melting point of HDPE is not that high so could easily be melted to form the liquid state. The water absorption rate of HDPE is low. Thus there is no need of high temperature to vaporise the water content away from it. Out of the whole type of plastics those which are suitable are polyethylene [PE], polypropylene [PP], polystyrene [PS].

\section{Extraction of Pyrolysed Oil from HDPE}

\subsection{Methodology}

In our experiments, commercially available shredded plastics were procured and washed before pyrolysis. One of the most favorable and effective disposing method is pyrolysis, which is environmental friendly and efficient way. Pyrolysis is the thermal degradation of solid wastes at high temperatures $\left(300-900^{\circ} \mathrm{C}\right)$ in the absence of air (and oxygen). As the structure of products and their yields can be considerably modified by catalysts, results of pyrolysis in the absence of catalyst were presented in this article Pyrolysis of waste plastics was carried out in an indigenously designed and fabricated reactor. Shows the scheme of the process involved in the experiments and the photograph of the experimental set up respectively. Waste plastics had been procured form the commercial source and stored in a raw material storage unit. Raw material was then fed in the reactor commenced at a temperature of $350^{\circ} \mathrm{C}$. The gaseous products resulting from the pyrolysis of the plastic wastes is supplied to the catalyst of Potassium permanganate. Then the burned plastic gas condensed in a water cooled condenser to liquid fuel and collected for experiments. The steps are given below:

1. Identification of waste plastics. (PE/PP/PS/LDPE/HDPE/ABS)

2. Subjecting the waste plastic for pyrolysis process.

3. Condensation of the gas to obtain liquid fuel.

4. Conversion of liquid fuel into its pure form (diesel etc.) by the process of distillation.

\subsubsection{Collection \& Identification of Waste Plastic}

The collection of waste plastic is quite an easy task as compared to other wastes, the plastic wastes are abundant and can be obtained in large quantities from the households, roadsides, hospitals, hotels etc. Usually they are manufactured in the form of plastic bags, saline bottles, plastic tools, chairs and other components which we usually come across in our day to day life. These plastics could be collected or usually purchased at Rs.10 to $15 / \mathrm{kg}$ after being shredded and washed properly. 


\subsubsection{Subjecting the Waste Plastic for Pyrolysis Process}

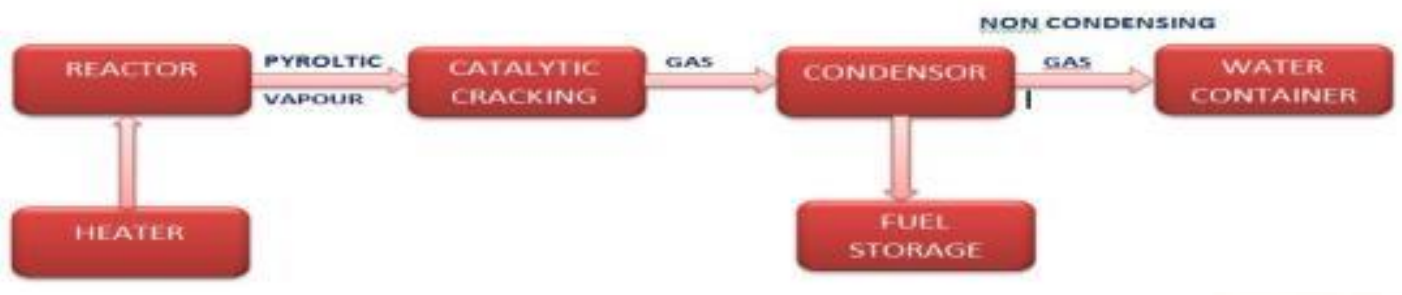

Fig 3.1: block diagram of pyrolysis process

The pyrolysis is a simple process in which the organic matter is subjected to higher temperature about $300^{\circ} \mathrm{C}$ to $500^{\circ} \mathrm{C}$ in order to promote thermal cracking of the organic matter so as to obtain the end products in the form of - liquid, char and gas in absence of oxygen.

\subsubsection{CONDENSATION OF GAS TO OBTAIN RAW FUEL}

After heating the waste plastic at a temperature of about $300{ }^{\circ} \mathrm{C}$ to $500^{\circ} \mathrm{C}$ in the reactor the gas is allowed to escape through the outlet dipped into the water containing jar so as to condense the fumes to obtain the liquid fuel floating over the surface, Which is further taken out through the outlet provide to the water containing jar.

\subsubsection{CONVERSION OF LIQUID FUEL INTO ITS PURE FORM BY THE PROCESS OF DISTILLATION}

Once the liquid fuel is obtained it is further subjected to distillation process so as to obtain the fuel i.e. diesel in its pure form by removing the impurities present in it which can be then tested into diesel engines for its efficiency. Here we used vacuum distillation process. Vacuum distillation is a method of distillation whereby the pressure above the liquid mixture to be distilled is reduced to less than its vapour pressure (usually less than atmospheric pressure) causing evaporation of the volatile liquid.
This distillation method works on the principle that boiling occurs when the vapor pressure of a liquid exceeds the ambient pressure. Vacuum distillation is used with or without heating the mixture.

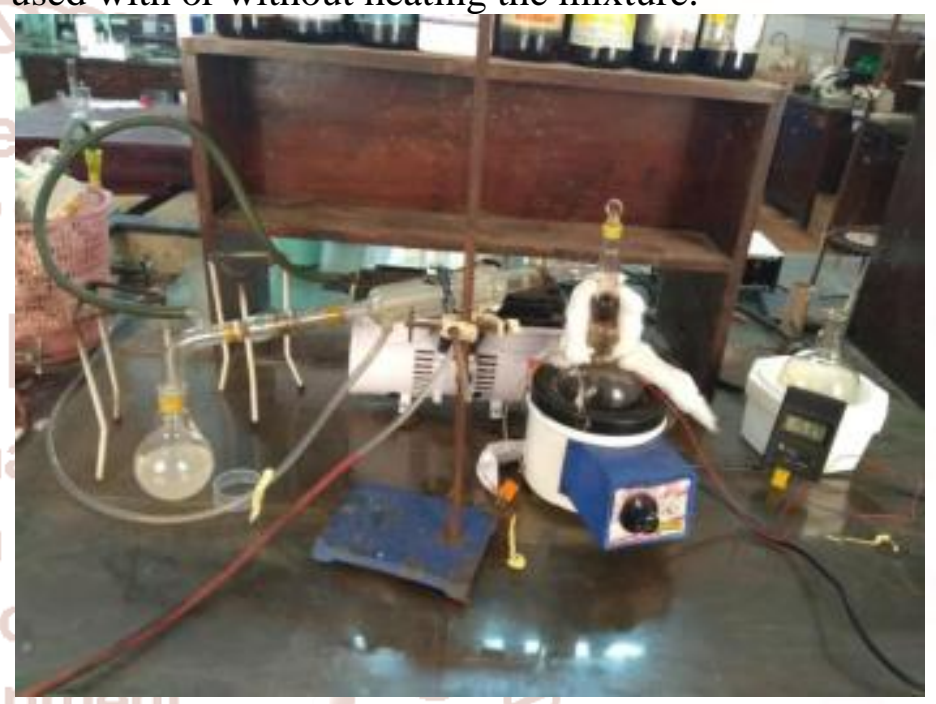

Fig 3.2: Distillation process

Pyrolysis is a thermochemical decomposition of organic material at elevated temperatures in the absence of oxygen (or any halogen). It involves the simultaneous change of chemical composition and physical phase, and is irreversible. The word is coined from the Greek-derived elements pyro "fire" and lysis "separating". 


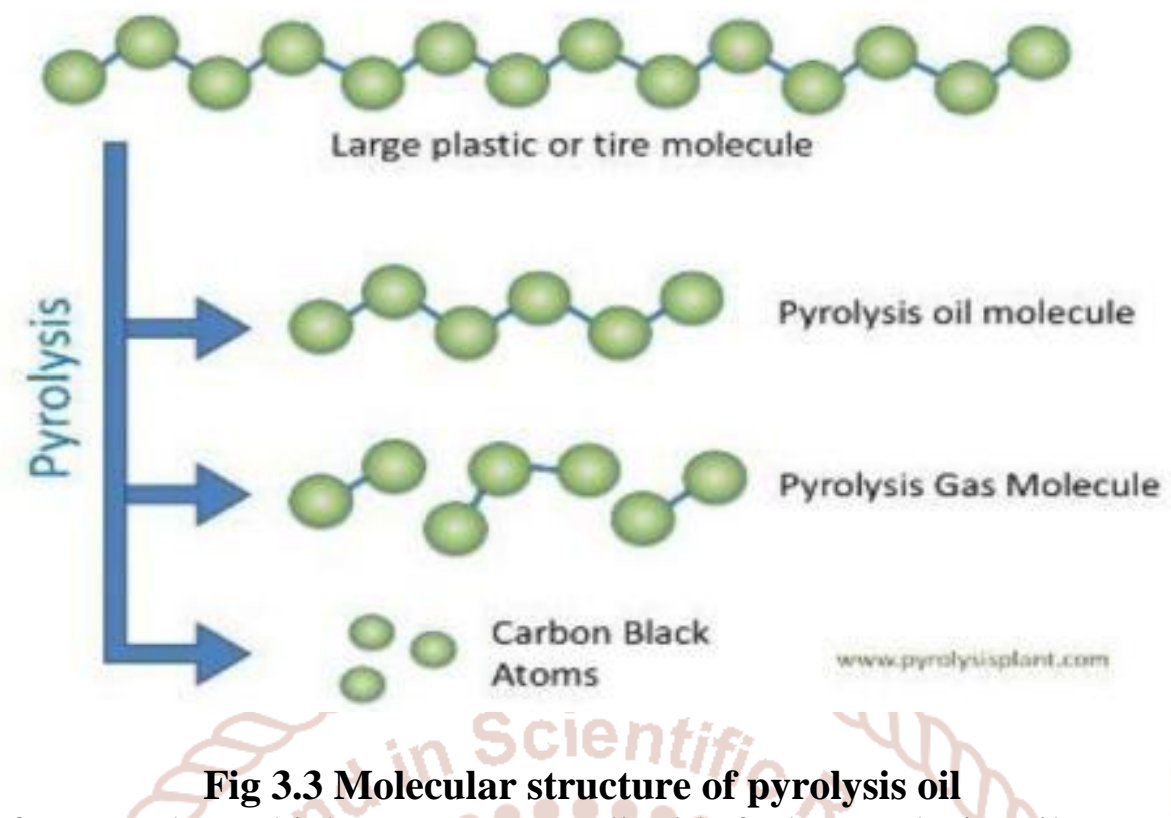

Pyrolysis differs from other high-temperature liquid fuel (pyrolysis oil), gases, and solid char. processes like combustion and hydrolysis in that it Variations in the pyrolysis method, biomass usually does not involve reactions with oxygen, water, characteristics, and reaction specifications will or any other reagents. In practice, it is not possible to produce varying percentages of these three products. achieve a completely oxygen- free atmosphere. Several technologies and methodologies can be used Because some oxygen is present in any pyrolysis for pyrolysis, including circulating fluid beds, system, a small amount of oxidation occurs. Bio-oil is produced via pyrolysis, a process in which biomass is rapidly heated to $450-500^{\circ} \mathrm{C}$ in an oxygen-free environment and then quenched, yielding a mix of entrained flow reactors, multiple hearth reactors, or vortex reactors. The process can be performed with or without a catalyst.

\subsection{DESCRIPTION OF COMPONENTS}

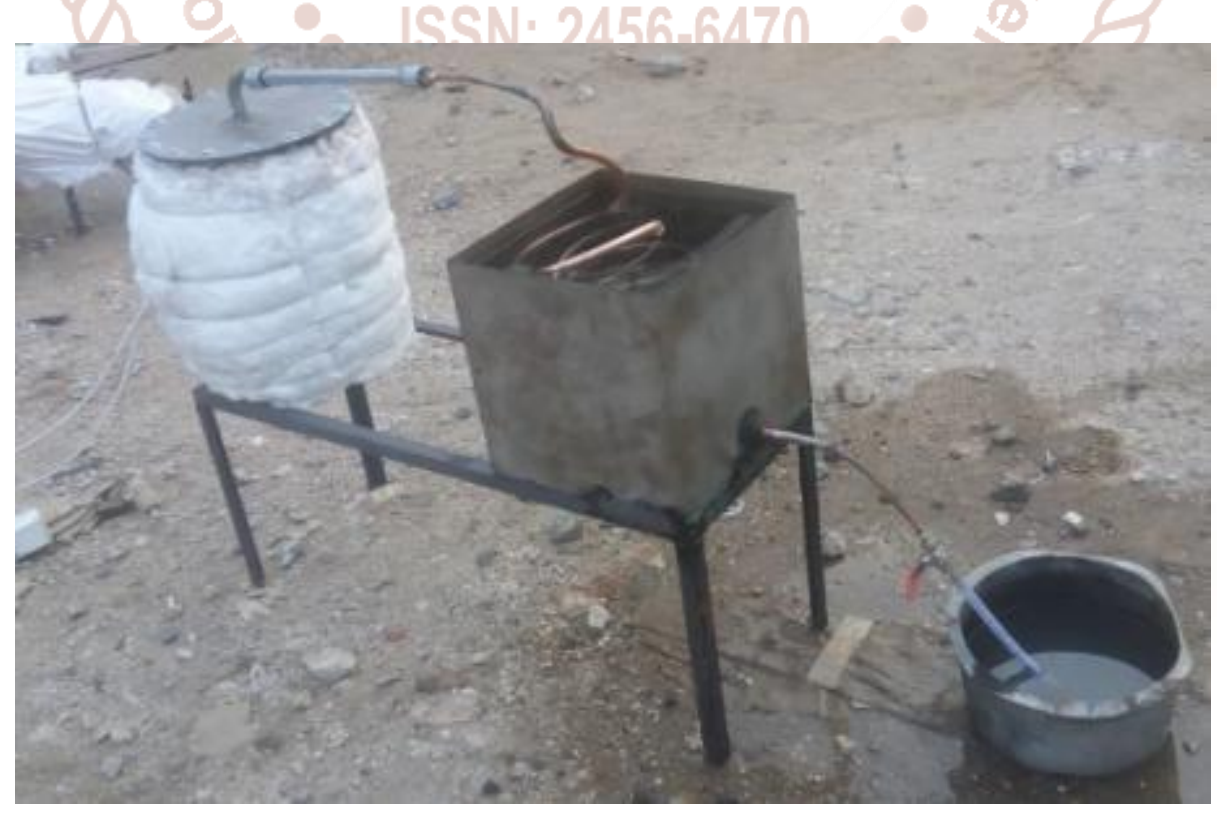

Fig 3.4 Experimental setup 


\subsubsection{COMBUSTION CHAMBER}

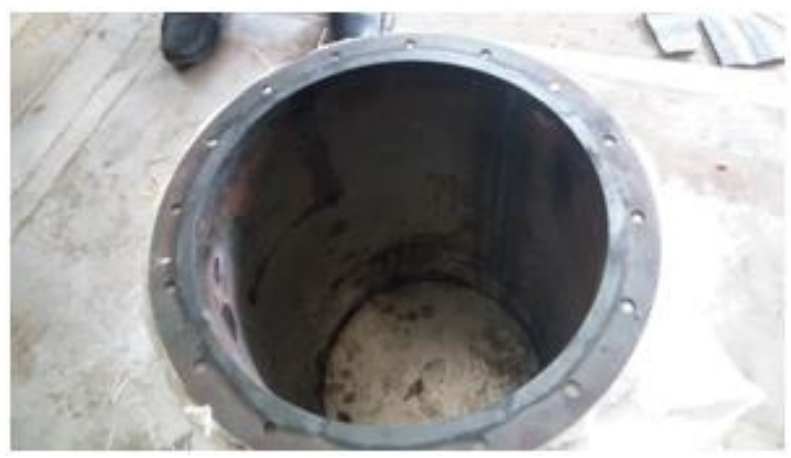

Fig 3.5 Combustion chamber

latent heat to surroundings for transferring from gaseous to liquid state.

Diameter of the copper wire $=12 \mathrm{~mm}$

No: of coils in condenser $\quad=5$

\subsubsection{ELECTRICAL HEATING COIL}

A heating coil transforms electricity into heat through the process of resistive or Joule heating. Electric current passing through the conductor experiences resistance resulting in heating of the element. Metallic heating element may be ribbon or wire, straight or

Combustion chamber is a cast iron chamber meant to melt the plastic fed into it. The combustion chamber should sustain all the heat fed to it without any cracking. The heating is provided with heating coil. The vessel is cylindrical with a lid to feed the plastic to it. The lid at the top is bolted to the chamber. This is the chamber in which the actual process of pyrolysis occurs.

\section{Height of the chamber}

Diameter of the chamber

Height of the cylinder from ground $=300 \mathrm{~mm}$ No: of bolts at the top of the chamber $=16$

\subsubsection{CONDENSER}

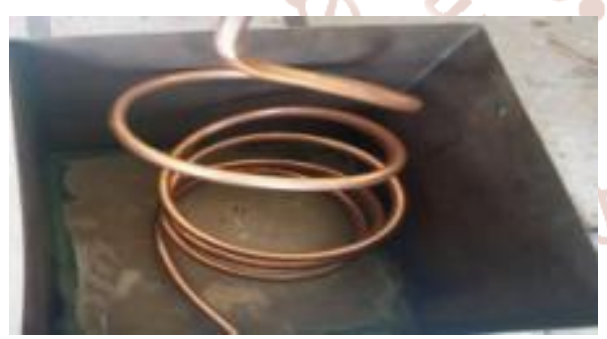

Fig 3.6 Condenser

The condenser is made of copper tube. The fumes coming out of the chamber is to be condensed to obtain the raw pyrolysed fuel. The copper tube is encapsulated with water to form the required condenser. The copper tube with water form the heat exchanger. This heat exchanger effectively functions as a condenser. In systems involving heat transfer a condenser is a device that is used to condense a substance from its gaseous state to liquid state by cooling. The substance that gets cooled releases its coiled in nature. They are commonly used in toasters, hair dryers, furnaces for heating purpose, floor heating etc. The electrical heating element currently selected is wired type.

The heating coil which is selected now is made up of Nichrome. The selected alloy contains $80 \%$ nickel and $20 \%$ chromium. Nichrome is selected because of its high resistive properties. The higher resistance offers efficient heating.

Power of heater $=2000$ watts

\subsection{WORKING}

The plastic selected specifically HDPE is fed to the chamber. The plastic is fed to the chamber through the lid at the top of the chamber. The lid of the chamber is properly bolted once the plastic is fed into the chamber. About $5 \mathrm{~kg}$ of plastic is fed once to the chamber. Then the electrical heating coil wound around the chamber is switched on. This coil supplies enough heat to melt the plastic fed into the chamber. Continuous melting leads to formation of liquid melted plastic. Further heating of the melted plastic leads to the formation of gaseous fumes. This fumes escapes out of the chamber to accumulate in the copper tube. Water is poured around the copper tube for condenser setup. Enough time is provided

to let the gas accumulate in the copper tube by closing the valve at the end of the condenser setup. The water around the copper tube cools the fumes in it. The first signs of raw fuel comes after 20 minutes of continuous power supply. The gate valve is opened once in every 5 minutes. Each time when the valve is opened about $20 \mathrm{ml}$ to $30 \mathrm{ml}$ of raw fuel is collected. This raw fuel is to be distilled.

\section{Performance Analysis of Distilled Oil in Computer Interfaced IC Engine Test Rig}


The distilled oil is tested for its performance, efficiencies and emissions. The oil blended with diesel in two different compositions are made to run in a Computer interfaced IC engine test rig. First the oil is blended with diesel and made up to 1litre

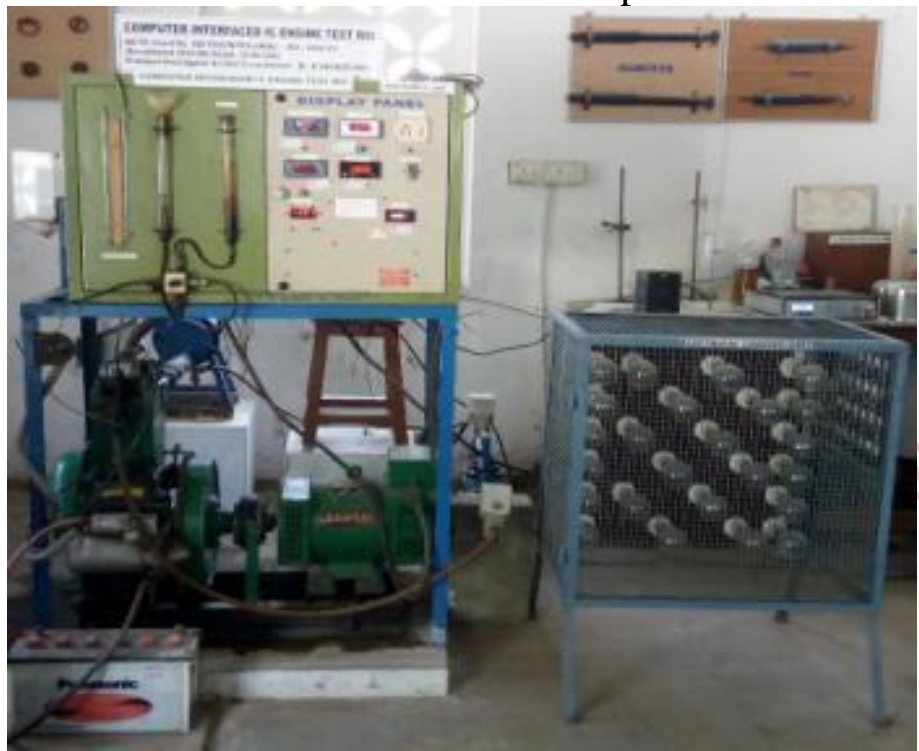

Fig 5.1 Computer interfaced IC engine test rig

\subsection{Blending Of Pyrolysed Oil with Diesel}

Blending is the process of mixing different ingredients smoothly and inseparably to obtain a particular kind of quality. In our project, we blend our pyrolysed oil with diesel. Two different compositions are made by blending. First a mixture of $25 \mathrm{~mL}$ pyrolysed oil with $975 \mathrm{~mL}$ of diesel is made to make a blend of 1L. Again a mixture of 50mL pyrolysed oil with $950 \mathrm{~mL}$ of diesel is made to make a blend of $1 \mathrm{~L}$. Once the blends are prepared, it's ready for performance and emission testing. The $25 \mathrm{~mL}$ oil blend is termed as B2.5 and $50 \mathrm{~mL}$ blend is termed as B5.

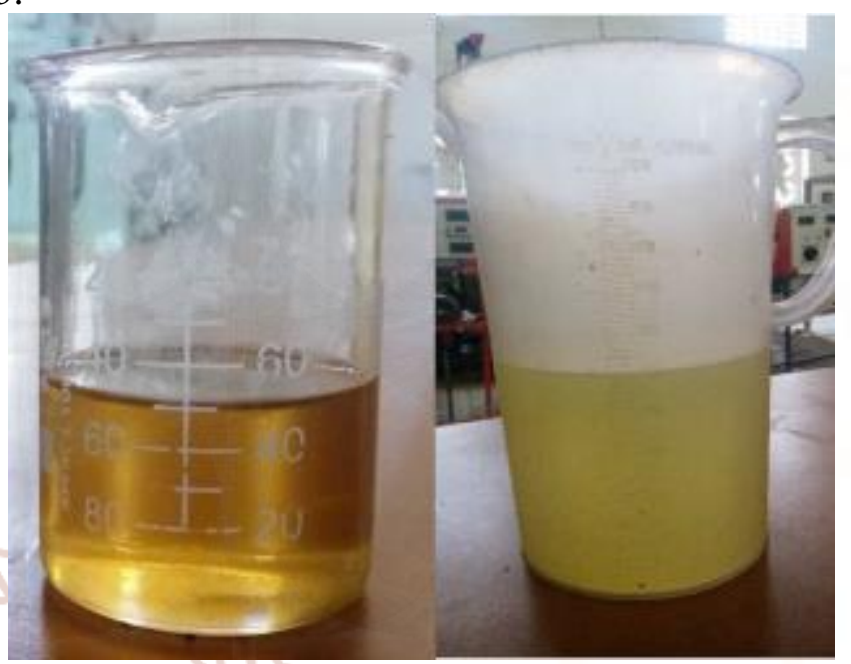

Fig 5.2 Distilled oil

Fig 5.3 Blend oil

\subsubsection{Performance and Emission Test of Distilled Oil}

Pure 1L of diesel is made to run in the IC engine for $10 \mathrm{~min}$. The engine is made to run continuously for about $10 \mathrm{~min}$ at a load of $0 \mathrm{~V}$, the manomatric reading, current, crank speed and the various gaseous emission are tested. The same experimental procedure is repeated for loads of $500 \mathrm{~V}, 1000 \mathrm{~V}$, of diesel. The same procedure is repeated for the 2diffirent blends B2.5 and B5 prepared. Thus the performance and emission of the blend fuel could be calculated.

\section{RESULTS AND INFERENCES}

\subsection{PERFORMANCE CHARACTERISTICS OF DIESEL}

Table 6.1(a) Performance characteristics of diesel

\begin{tabular}{|l|l|l|l|l|l|l|l|}
\hline S.NO & $\begin{array}{l}\text { Electrical } \\
\text { Load (kW) }\end{array}$ & Voltage (V) & $\begin{array}{l}\text { Speed } \\
\text { (rpm) }\end{array}$ & Fuel Consumption & $\begin{array}{l}\text { Manometric } \\
\text { Reading }\end{array}$ & \\
\cline { 5 - 7 } & & & & h1 (cm) & $\mathbf{h 2}(\mathbf{c m})$ & current (A) \\
\hline 1 & 0.5 & 220 & 1570 & 65 & 70 & 92 & 0 \\
\hline 2 & 1 & 220 & 1528 & 58 & 70 & 91 & 2 \\
\hline 3 & 1.5 & 220 & 1516 & 49 & 70 & 91 & 3.9 \\
\hline 4 & 2 & 220 & 1502 & 43 & 70 & 91 & 5.9 \\
\hline 5 & 2.5 & 220 & 1486 & 37 & 70 & 91 & 9 \\
\hline
\end{tabular}

Table 6.1(b) Performance characteristics of diesel

\begin{tabular}{|l|l|l|l|l|l|l|l|l|l|l|}
\hline BP & TIME & TFC & SFC & FP & nBTE & IP & nmech & BMEP & IMEP & nITE \\
\hline 0 & 65 & 0.46 & - & 5.81 & - & 1.75 & - & 0 & 521 & 30.12 \\
\hline 0.5 & 58 & 0.534 & 1.068 & 6.75 & 7.40 & 2.25 & 22.25 & 148 & 670 & 33.33 \\
\hline 1 & 49.11 & 0.608 & 0.608 & 7.68 & 13.01 & 2.75 & 36.36 & 306 & 841 & 35.31 \\
\hline
\end{tabular}


International Journal of Trend in Scientific Research and Development (IJTSRD) ISSN: 2456-6470

Reading No: 2

\begin{tabular}{|l|l|l|l|l|l|l|l|l|l|l|}
\hline 1.5 & 43.46 & 0.688 & 0.451 & 8.7 & 17.25 & 3.25 & 46.15 & 462 & 1001 & 37.4 \\
\hline 2 & 37.40 & 0.799 & 0.40 & 10.1 & 19.81 & 3.75 & 53.33 & 623 & 1167 & 37.2 \\
\hline
\end{tabular}

1. Total fuel consumption, (TFC) $=(10 / \mathrm{t}) * \gamma *(36 / 10) \mathrm{kg} / \mathrm{hr}$

$$
=(10 / 58) * 0.84 *(36 / 10)=0.534
$$

2. Specific fuel consumption $\quad=\mathrm{TFC} / \mathrm{BP} \mathrm{kg} / \mathrm{kWhr}$

$$
=0.534 / 0.5
$$

$=1.068 \mathrm{~kg} / \mathrm{kWhr}$

3. Brake thermal efficiency $(\mathrm{nBTE})=\mathrm{BP} /$ fuel power

Fuel power $=\left(\mathrm{TFC}^{*} \mathrm{Cv}\right) / 3600 \mathrm{~kW}$

$$
=0.5 / \text { fuel power }
$$

$$
\begin{aligned}
& =(0.534 * 45500) / 3600 \\
& =6.749 \mathrm{~kW}
\end{aligned}
$$

Brake thermal efficiency $(\mathrm{nBTE}) \quad=0.5 / 6.749=7.40 \%$

Area of orifice

$$
\begin{aligned}
& =\left(\pi^{*} \mathrm{~d} 2\right) / 4 \\
& =\left(\pi^{*} 0.07\right) / 4 \\
& =0.00385 \mathrm{~m} 2
\end{aligned}
$$

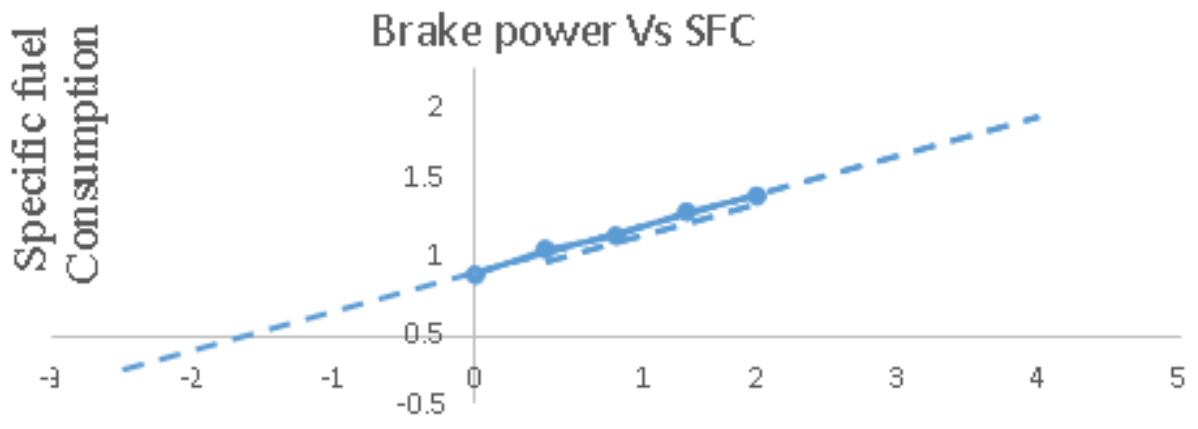

Rraba nomiar

\section{Fig 6.1 Brake power vs SFC}

(From this graph the frictional power is taken as FB $=1.75 \mathrm{~kW}$ )

4. Indicated power (IP)

5. Mechanical efficiency (nmech)

6. Indicated thermal efficiency, (nITE)

7. Brake mean effective pressure, (BMEP)

8. Indicated mean effective pressure, (IMEP)

$$
\begin{aligned}
& =B P+F P \\
& =0.5+1.75=2.25 \mathrm{~kW}
\end{aligned}
$$

$=\mathrm{BP} / \mathrm{IP}$

$=0.5 / 2.25$

$$
=22.25 \%
$$

$=$ Indicated power/ fuel power

$=2.25 / 6.749$

$=33.3 \%$

$=(\mathrm{BP} * 2 * 60) / \mathrm{LAN}$

$=\{(0.5 * 2 * 60)\} /\{(0.0667 * 0.00385 * 1528)\}$

$=148.82 \mathrm{kN} / \mathrm{m}^{2}$

$=($ IP* $2 * 60) /$ LAN

$=\{(2.25 * 2 * 60)\} /$ 
International Journal of Trend in Scientific Research and Development (IJTSRD) ISSN: 2456-6470 $\{(0.0667 * 0.00385 * 1528)\}$

$=669.69 \mathrm{kN} / \mathrm{m}^{2}$

\subsection{PERFORMANCE CHARACTERISTICS OF B5 BLEND}

Table 6.2 (a) Performance characteristics of B5 blend

\begin{tabular}{|c|c|c|c|c|c|c|c|}
\hline \multirow[b]{2}{*}{ S.NO } & \multirow{2}{*}{$\begin{array}{l}\text { LOAD } \\
\quad(\mathrm{V})\end{array}$} & \multicolumn{2}{|c|}{$\begin{array}{l}\text { SPEED } \\
\text { (rpm) }\end{array}$} & \multirow{2}{*}{$\begin{array}{c}\text { TIME FOR 10CC } \\
\text { CONSUMPTION } \\
(\mathrm{s})\end{array}$} & \multicolumn{3}{|c|}{$\begin{array}{c}\text { MANOMETRIC } \\
\text { READING }\end{array}$} \\
\hline & & CAM & CRANK & & $\begin{array}{c}\text { h1 } \\
(\mathrm{cm})\end{array}$ & $\begin{array}{c}\text { h2 } \\
\text { (cm) }\end{array}$ & $\begin{array}{l}\mathbf{H m} \\
(\mathbf{m})\end{array}$ \\
\hline 1 & 0 & 768 & 1536 & 51 & 70 & 89 & 0.795 \\
\hline 2 & 500 & 765 & 1530 & 53 & 72 & 89.5 & 0.8075 \\
\hline 3 & 1000 & 756 & 1512 & 50.83 & 72 & 89.5 & 0.8075 \\
\hline 4 & 1500 & 750 & 1500 & 43.07 & 72 & 89.5 & 0.8075 \\
\hline 5 & 2000 & 745 & 1490 & Gle 38.68 & 74 & 88 & 0.81 \\
\hline
\end{tabular}

Table 6.2 (b) Performance characteristics of B5 blend

\begin{tabular}{|c|c|c|c|c|c|c|c|}
\hline S.No & $\begin{array}{c}\mathbf{B P} \\
(\mathbf{k W})\end{array}$ & $\begin{array}{c}\text { TFC } \\
(\mathbf{k g} / \mathbf{h r})\end{array}$ & $\begin{array}{c}\mathbf{S F C} \\
(\mathbf{k g} / \mathbf{k W h r})\end{array}$ & $\begin{array}{c}\mathbf{F P} \\
(\mathbf{k W})\end{array}$ & $\begin{array}{c}\mathbf{M A} \\
(\mathbf{k g} / \mathbf{h r})\end{array}$ & $\begin{array}{c}\mathbf{M F} \\
(\mathbf{k g} / \mathbf{h r})\end{array}$ & $\mathbf{A} / \mathbf{F}$ \\
\hline 1 & 0 & 0.5929 & 0 & 1.95 & 23.4 & 30.42 & 39.46 \\
\hline 2 & 0.5 & 0.5705 & 1.141 & 1.95 & 20.2 & 30.12 & 35.4 \\
\hline 3 & 1 & 0.5949 & 0.5949 & 1.95 & 18.9 & 29.8 & 31.77 \\
\hline 4 & 1.5 & 0.7021 & 0.4680 & 1.95 & 18.1 & 29.3 & 25.77 \\
\hline 5 & 2 & 0.7817 & 0.3908 & 1.95 & 16.7 & 28.1 & 21.363 \\
\hline
\end{tabular}

Table 6.2 (c) Performance characteristics of b5 blend

\begin{tabular}{|c|c|c|c|c|c|c|c|}
\hline S.No & $\underset{(\mathbf{k W})}{\mathbf{I P}}$ & $\begin{array}{l}\text { nme } \\
\text { ch } \\
(\%)\end{array}$ & $\begin{array}{l}\text { nBT } \\
\text { E } \\
(\%)\end{array}$ & $\begin{array}{l}\text { nIT } \\
\mathbf{E} \\
(\%)\end{array}$ & $\begin{array}{c}\text { Fuel } \\
\text { Power } \\
\text { (FP) }\end{array}$ & $\begin{array}{r}\text { BMEP } \\
\left(\mathrm{kN} / m^{2}\right)\end{array}$ & $\begin{array}{c}\text { IMEP } \\
\left(\mathrm{kN} / m^{2}\right)\end{array}$ \\
\hline & 1.95 & 0 & 0 & 26.03 & 7.49 & 0 & 593.2 \\
\hline 2 & 2.45 & 20.4 & 6.93 & 33.98 & 7.21 & 152.7 & 757.19 \\
\hline 3 & 2.95 & 33.8 & 13.29 & 39.38 & 7.49 & 309 & 911.7 \\
\hline 4 & 3.45 & 43.4 & 16.90 & 38.89 & 8.87 & 467.2 & 1074.7 \\
\hline 5 & 3.95 & 50.6 & 20.24 & 40.02 & 9.87 & 627.2 & 1238.8 \\
\hline
\end{tabular}

\section{READING NO: 2}

1. Total fuel consumption

2. Specific fuel consumption
$=(10 / \mathrm{t}) * \gamma^{*}(3600 / 1000) \mathrm{kg} / \mathrm{hr}$

$=(10 / 53) * 0.84 *(3600 / 1000)$

$=0.5705 \mathrm{~kg} / \mathrm{hr}$

$=\mathrm{TFC} / \mathrm{BP} \mathrm{kg} / \mathrm{kWhr}$ 
$=0.5705 / 0.5$

$=1.141 \mathrm{~kg} / \mathrm{kWhr}$

3. Actual mass of air, (ma)

$=c^{*} \rho a * A *(2 g h a) 1 / 2 * 3600$

$=\{0.62 * 1.23 * 1.227 * 10-4$

$*(2 * 9.81 * 0.1842) 1 / 2 * 3600\}$

$=20.2 \mathrm{~kg} / \mathrm{hr}$

4. Theoretical mass of air, (mf)

$=\pi d^{2} / 4 * L(N / 2) \rho a * 60 \mathrm{~kg} / \mathrm{hr}$

$=\pi(0.08)^{2} / 4 * 0.11 *(1530 / 2) * 1.23 * 60$

$=30.12 \mathrm{~kg} / \mathrm{hr}$

5. Air fuel ratio, (A/F)

$=$ actual air intake/TFC

$=20.2 / 0.5705=35.4$

6. Indicated power (IP)

$=\mathrm{BP}+\mathrm{FP}=0.5+1.95=2.45 \mathrm{~kW}$

7. Mechanical efficiency (nmech)

$=\mathrm{BP} / \mathrm{IP}=0.5 / 2.45=20.4 \%$

8. Brake thermal efficiency (nBTE)

$=\mathrm{BP} /$ fuel power

$=0.5 /$ fuel power

9. Fuel power

$=(\mathrm{TFC} * \mathrm{CV}) / 3600=(0.5705 * 45500) / 3600$

$=7.21 \mathrm{~kW}$

Brake thermal efficiency, (nBTE) of $T F^{\prime}=0.5 / 7.21=6.93 \%$

Indicated thermal efficiency, (nITE) $\quad$ = Indicated power/fuel power

$=2.45 / 7.21=33.98 \%$

10. Brake mean effective pressure, (BMEP)

$=(B P * 2 * 60) /$ LAN

$=\{(0.5 * 2 * 60)\} /$

$\{(0.0667 * 0.00385 * 1530)\}$

$=152.7 \mathrm{kN} / \mathrm{m}^{2}$

11. Indicated mean effective pressure, (IMEP)

$=(I P * 2 * 60) /$ LAN

$=\{(2.5 * 2 * 60)\} /$

$\{(0.0667 * 0.00385 * 1530$

$=757.19 \mathrm{kN} / \mathrm{m}^{2}$

\subsection{PERFORMANCE CHARACTERISTICS OF B2.5 BLEND}

Table6.3 (a) Performance characteristics of B2.5 blend

\begin{tabular}{|c|c|c|c|c|c|c|c|c|}
\hline \multirow{2}{*}{ S.NO } & \multirow{2}{*}{$\begin{array}{l}\text { BP } \\
(\mathbf{W})\end{array}$} & \multicolumn{2}{|c|}{$\begin{array}{l}\text { SPEED } \\
\text { (rpm) }\end{array}$} & \multirow{2}{*}{$\begin{array}{c}\text { FUEL } \\
\text { CONSUMPTION } \\
\text { TIME FOR 10CC } \\
\text { (s) }\end{array}$} & \multirow{2}{*}{$\begin{array}{c}\text { CURRENT } \\
\text { (A) }\end{array}$} & \multicolumn{3}{|c|}{$\begin{array}{c}\text { MANOMETRIC } \\
\text { READING }\end{array}$} \\
\hline & & CAM & CRANK & & & $\begin{array}{c}\text { h1 } \\
(\mathrm{cm})\end{array}$ & $\begin{array}{c}\text { h2 } \\
(\mathrm{cm})\end{array}$ & $\begin{array}{l}\text { hm } \\
\text { (m) }\end{array}$ \\
\hline
\end{tabular}


International Journal of Trend in Scientific Research and Development (IJTSRD) ISSN: 2456-6470

\begin{tabular}{|c|c|c|c|c|c|c|c|c|}
\hline 1 & 0 & 770 & 1540 & 104 & 0 & 76 & 88.8 & 0.824 \\
\hline 2 & 500 & 761 & 1522 & 59 & 198 & 76 & 88.9 & 0.824 \\
\hline 3 & 1000 & 756 & 1512 & 50.8 & 399 & 74.8 & 88.9 & 0.8185 \\
\hline 4 & 1500 & 750 & 1500 & 43.79 & 602 & 74.4 & 88.5 & 0.8145 \\
\hline 5 & 2000 & 745 & 1490 & 38.56 & 810 & 73.2 & 88.5 & 0.8085 \\
\hline
\end{tabular}

Table6.3 (b) Performance characteristics of B2.5 blend

\begin{tabular}{|c|c|c|c|c|c|c|c|}
\hline S.NO & $\begin{array}{c}\text { IP } \\
(\mathbf{k W})\end{array}$ & nmech & ПBTE & nITE & $\begin{array}{c}\text { FUEL } \\
\text { POWER } \\
\text { (FP) }\end{array}$ & $\begin{array}{c}\text { BMEP } \\
\left(\mathrm{kN} / m^{2}\right)\end{array}$ & $\begin{array}{r}\text { IMEP } \\
\left(\mathrm{kN} / m^{2}\right)\end{array}$ \\
\hline 1 & 1.8 & 0 & 0 & 49.04 & 3.67 & 0 & 546.19 \\
\hline 2 & 2.3 & 21.73 & 7.72 & 35.5 & 6.47 & 153.51 & 706.16 \\
\hline 3 & 2.8 & 35.71 & 13.29 & 37.23 & 7.52 & 309.06 & 865.36 \\
\hline 4 & 3.3 & 45.45 & 17.2 & 37.84 & 8.72 & 467.29 & 1028.05 \\
\hline 5 & 3.8 & 52.6 & 20.18 & 38.34 & 9.91 & 627.24 & 1191.76 \\
\hline
\end{tabular}

Table6.3 (c) Performance characteristics of B2.5 blend

\begin{tabular}{|c|c|c|c|c|c|c|c|}
\hline S.NO & $\begin{array}{c}\mathbf{B P} \\
(\mathbf{k W})\end{array}$ & $\begin{array}{c}\text { TFC } \\
(\mathrm{kg} / \mathrm{hr})\end{array}$ & $\begin{array}{c}\text { SFC } \\
(\mathrm{kg} / \mathrm{kWhr})\end{array}$ & $\begin{array}{c}\mathbf{F P} \\
(\mathbf{k W})\end{array}$ & $\begin{array}{c}\text { Ma } \\
(\mathrm{kg} / \mathrm{hr})\end{array}$ & $\begin{array}{c}\text { Mf } \\
(\mathrm{kg} / \mathrm{hr})\end{array}$ & $\mathbf{A} / \mathbf{F}$ \\
\hline 1 & 0 & 0.2907 & $D \in 0$ CIO & On1.8 & 20.81 & 21.46 & 71.58 \\
\hline 2 & 0.5 & 0.5125 & 1.025 & 1.8 & 18.12 & 19.31 & 35.35 \\
\hline 3 & 1 & 0.5952 & 0.5952 & 1.8 & 16.43 & 16.92 & 27.6 \\
\hline 4 & 1.5 & 0.6905 & 0.4603 & 1.8 & 14.32 & 16.1 & 20.73 \\
\hline 5 & 2 & 0.7842 & 0.3921 & 1.8 & 12.18 & 14.21 & 15.53 \\
\hline
\end{tabular}

\section{READING NO: 2}

1. Total fuel consumption

2. Specific fuel consumption

3. Actual mass of air, (ma)

$$
\begin{aligned}
= & (10 / \mathrm{t}) * \gamma^{*}(3600 / 1000) \mathrm{kg} / \mathrm{hr} \\
= & (10 / 0.84) *(3600 / 1000)=0.5125 \mathrm{~kg} / \mathrm{hr} \\
= & \mathrm{TFC} / \mathrm{BP} \mathrm{kg} / \mathrm{kWhr} \\
= & 0.5125 / 0.5=1.025 \mathrm{~kg} / \mathrm{kWhr} \\
= & c d^{*} \rho a^{*} A^{*}(2 \mathrm{gha})^{1 / 2} * 3600 \\
= & \left\{0.62 * 1.23^{*} 1.227^{*} 10^{4}\right\}^{*} \\
& \left\{(2 * 9.81 * 161.51)^{1 / 2 * 3600\}}\right. \\
= & 18.12 \mathrm{~kg} / \mathrm{hr}
\end{aligned}
$$


4. Theoretical mass of air, $(\mathrm{mf})$

$$
\begin{aligned}
& =\pi d^{2} / 4 * \mathrm{~L}(\mathrm{~N} / 2) \rho a * 60 \mathrm{~kg} / \mathrm{hr} \\
& =\pi(0.08)^{2} / 4 * 0.11 *(1522 / 2) * 1.23 * 60 \\
& =19.31 \mathrm{~kg} / \mathrm{hr} \\
& =\text { actual air intake/TFC } \\
& \quad=18.12 / 0.5125=35.35 \\
& =\mathrm{BP}+\mathrm{FP}=0.5+1.8=2.3 \mathrm{~kW} \\
& =\mathrm{BP} / \mathrm{IP}=0.5 / 2.3=21.73 \% \\
& =\mathrm{BP} / \text { fuel power }=0.5 / \text { fuel power } \\
& =(\mathrm{TFC} * \mathrm{CV}) / 3600 \mathrm{~kW} \\
& =(0.5125 * 45500) / 3600=6.47 \mathrm{~kW}
\end{aligned}
$$$$
\text { 5. Air fuel ratio, }(\mathrm{A} / \mathrm{F})
$$

6. Indicated power (IP)

7. Mechanical efficiency (nmech)

8. Brake thermal efficiency (nBTE)

Fuel power

Brake thermal efficiency (nBTE)

$=0.5 / 6.47=7.72 \%$

9. Indicated thermal efficiency, (nITE) = Indicated power/ fuel power

$=2.3 / 7.21=35.5 \%$

10. Brake mean effective pressure, $(B M E P)=(B P * 2 * 60) / L A N$

$$
\begin{aligned}
& =\{(0.5 * 2 * 60)\} /\{(0.0667 * 0.00385 * 1522)\} \\
& =153.51 \mathrm{kN} / \mathrm{m}^{2}
\end{aligned}
$$

11. Indi. mean effective pressure, $($ IMEP $)=(I P * 2 * 60) /$ LAN

$$
\begin{aligned}
& =\{(2.3 * 2 * 60)\} /\{(0.0667 * 0.00385 * 1522)\} \\
& =706.16 \mathrm{kN} / \mathrm{m}^{2} \mathrm{and}
\end{aligned}
$$

\subsection{COMPARISON OF PERFORMANCE BETWEEN DIESEL AND B5 BLEND}

\subsubsection{SPECIFIC FUEL CONSUMPTION}

From the graph it's very clear that the SFC value of B5 blend matches well with that of diesel. It's also clear that the SFC value of pyrolysed oil is a little less than that of pure diesel.

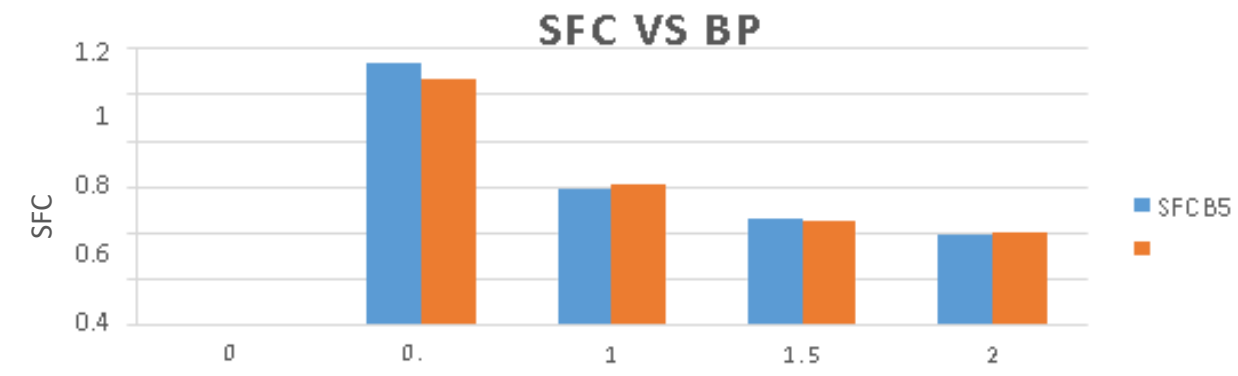

Fig 6.2 Specific fuel consumption vs BP 


\subsubsection{MECHANICAL EFFICIENCY}

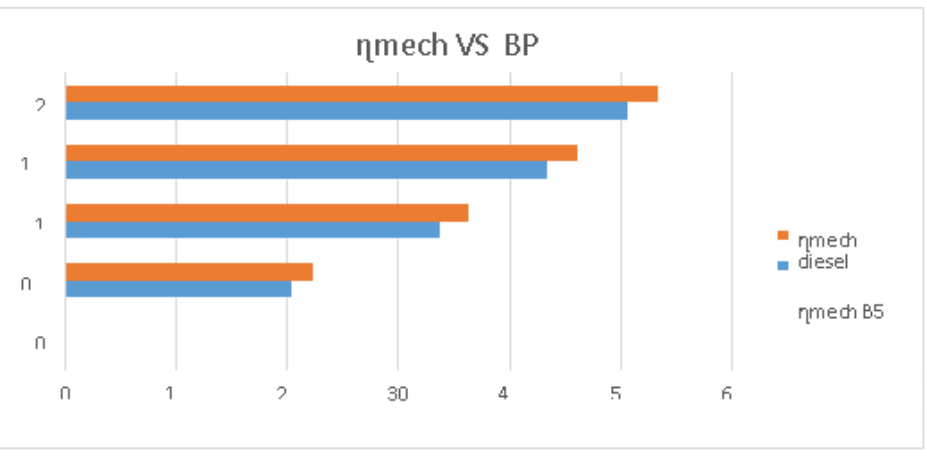

Fig 6.3 Mechanical efficiency vs BP

Mechanical efficiency of both the fuels increase with increase in load and both shows similar pattern of response to load variation. Also the mechanical efficiency of the blend is a little less than that of diesel.

\subsubsection{BRAKE THERMAL EFFICIENCY}

From the graph it's clear that both fuels show an increase in brake thermal efficiency with increase in load value. For BP values of 1 and 2 the efficiency of blend is a little higher than that of diesel while for the other two values efficiency of diesel is higher.

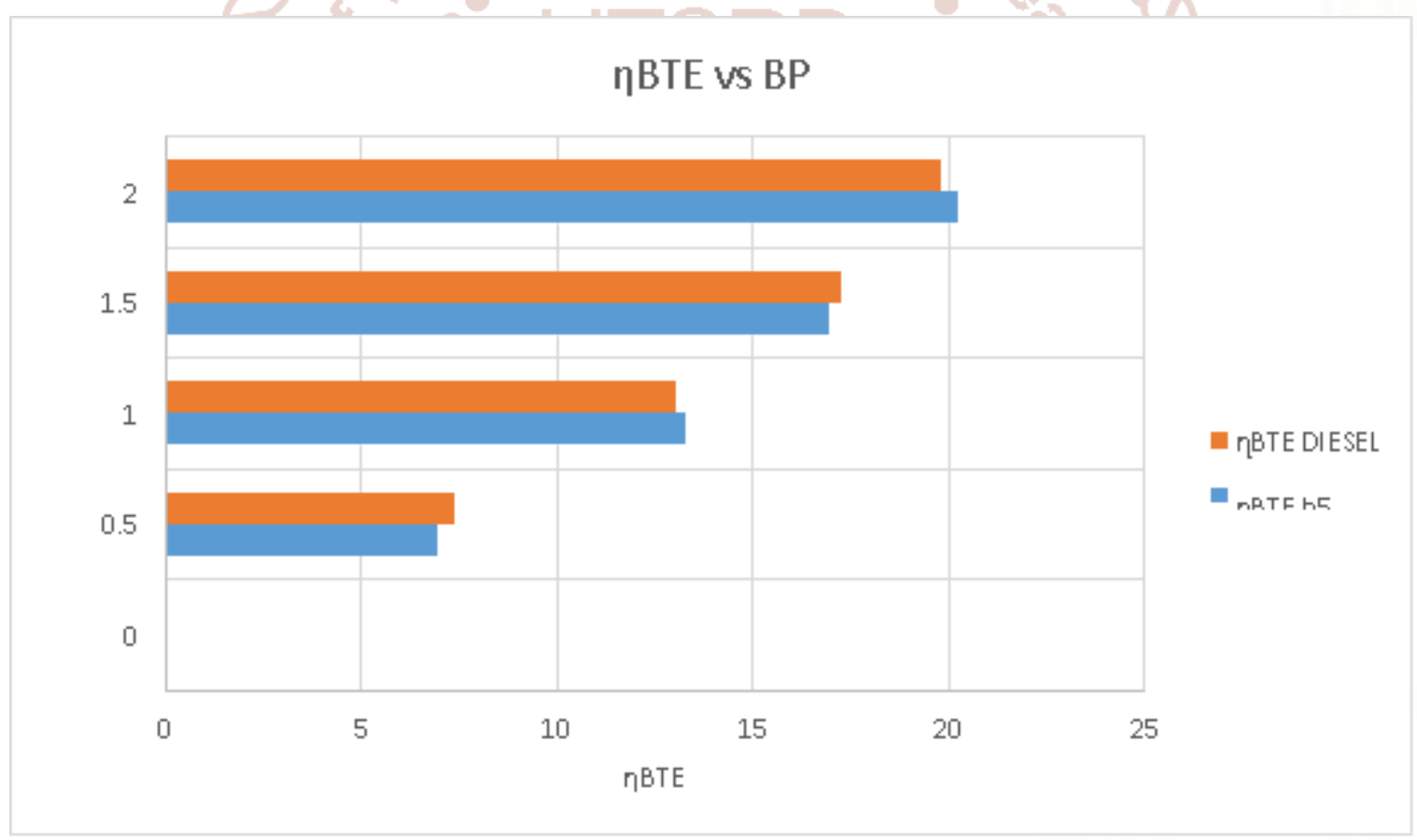

Fig 6.4 Brake thermal efficiency vs. brake power

\subsubsection{INDICATED THERMAL EFFICIENCY}

From the graph it's clear that the indicated thermal efficiency of the blend shows a sudden increase in its value with increasing value of BP. The efficiency value of the blend matches well with that of diesel for first 2 values of $\mathrm{BP}$ and for further increasing values of BP the efficiency of the blend is higher. 


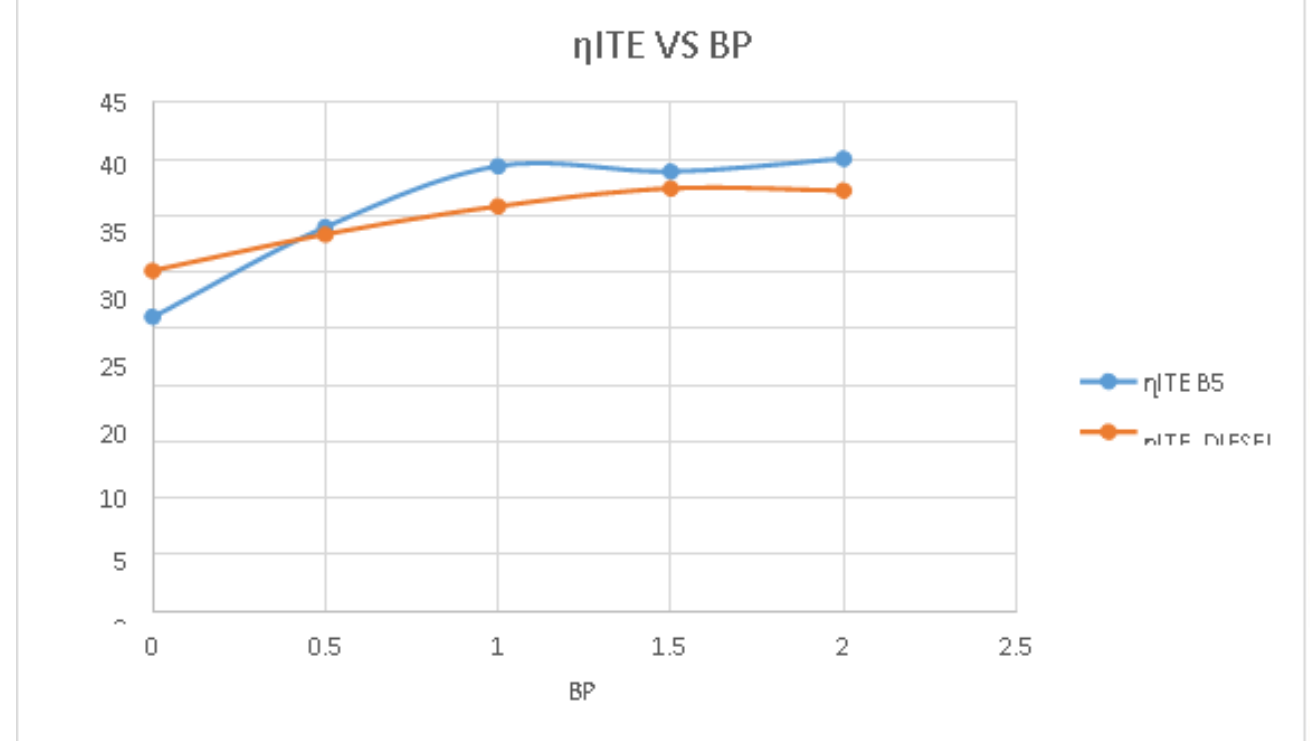

Fig 6.5 Indicated thermal efficiency vs. brake power

\subsubsection{BRAKE MEAN EFFECTIVE PRESSURE}

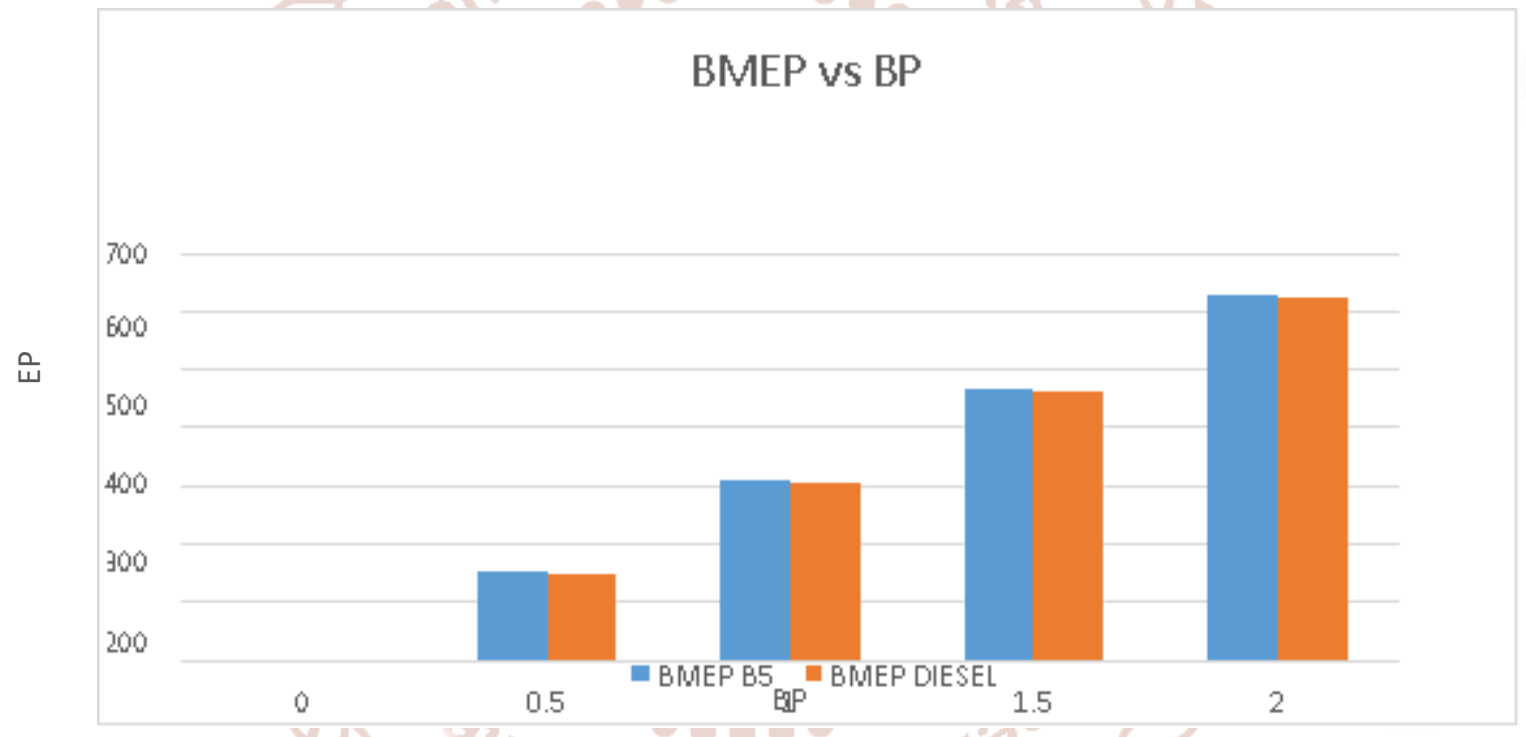

Fig 6.6 Brake mean effective pressure vs. brake power

Brake Mean Effective Pressure (BMEP) is another very effective yardstick for comparing the performance of an engine of a given type to another of the same type, and for evaluating the reasonableness of performance claims or requirements. The average (mean) pressure which, if imposed on the pistons uniformly from the top to the bottom of each power stroke, would produce the measured (brake) power output. BMEP is purely theoretical and has nothing to do with actual cylinder pressures. It is simply a tool to evaluate the efficiency of a given engine at producing torque from a given displacement. The graph shows the variation between BP and BMEP. The value of BMEP for both the fuels increases with increasing BP. Also both the fuels show close tolerances in their values.

\subsubsection{INDICATED MEAN EFFECTIVE PRESSURE}




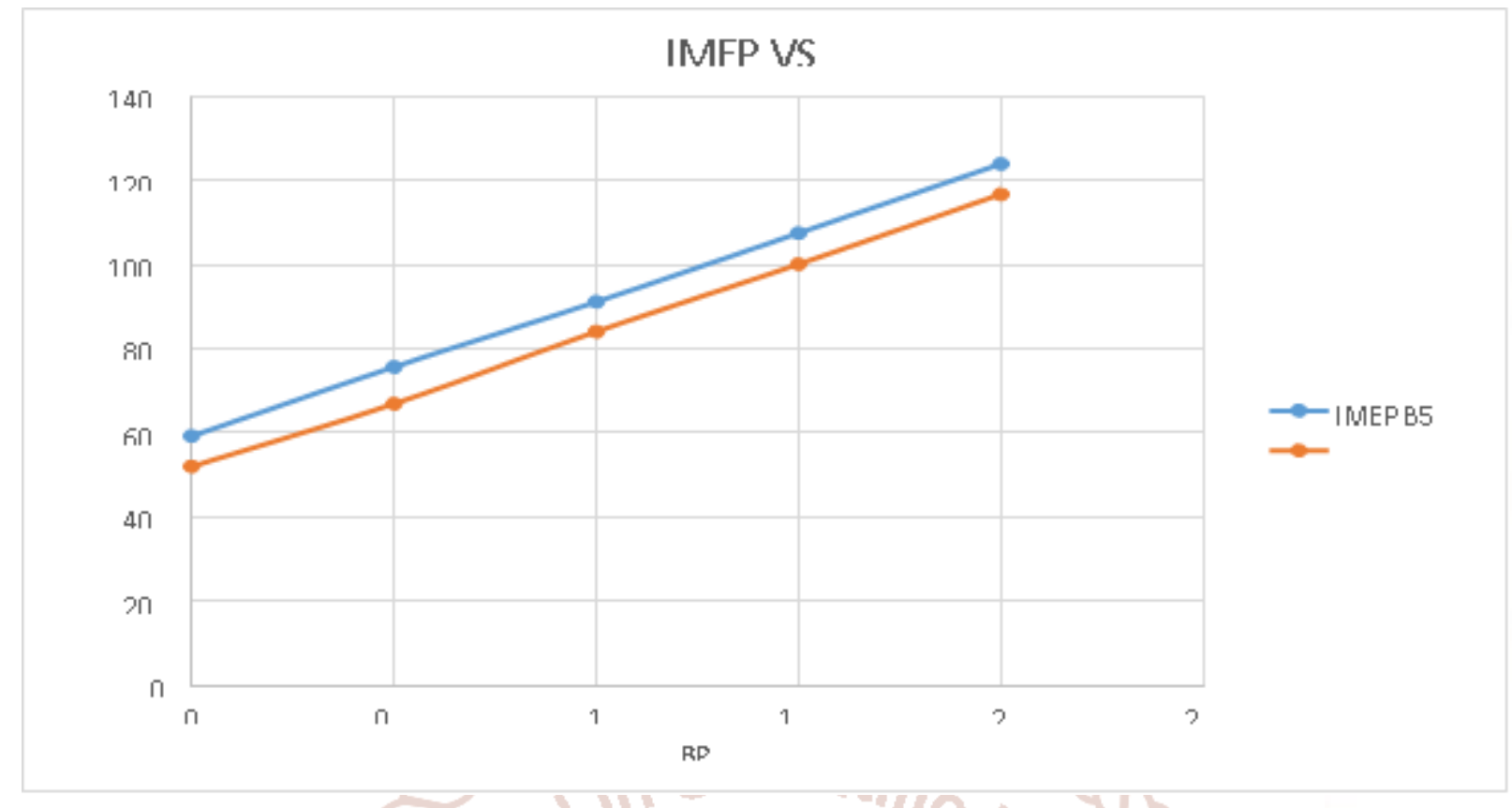

Fig 6.7 Indicated mean effective pressure vs brake power

Indicated Mean Effective Pressure (IMEP) is a fictitious pressure, such that if it acts during whole cycle, it would produce the same amount of work. The IMEP value of both the fuels increases with increase in BP. Here from the graph it's clear that the value of blend is higher than that of diesel.

\subsection{COMPARISON OF PERFORMANCE BETWEEN DIESEL AND B2.5 BLEND}

\subsubsection{SPECIFIC FUEL CONSUMPTION}

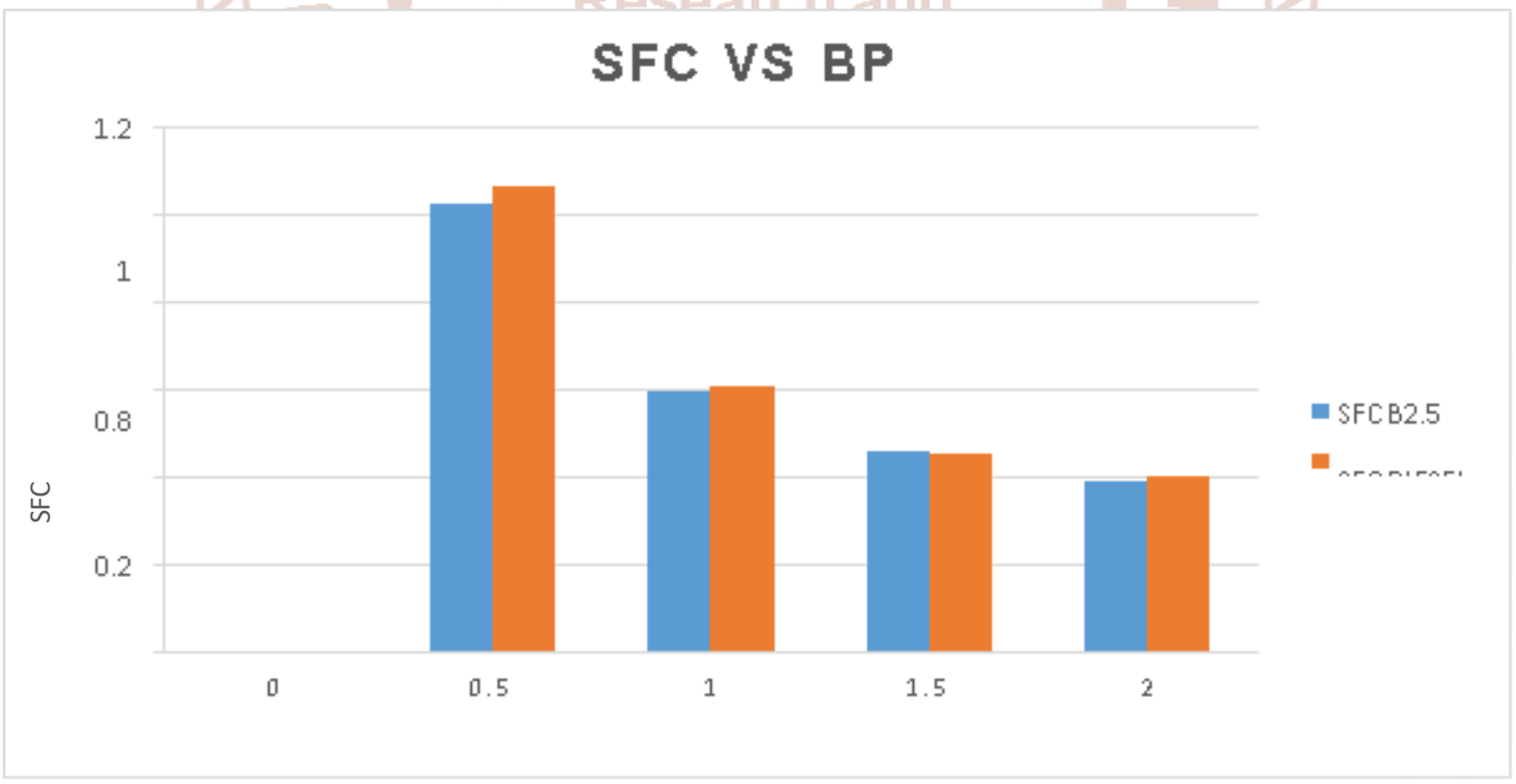

Fig 6.8 Specific fuel consumption vs. brake power

From the graph it's very clear that the value of SFC increases with increasing value of BP. Also the value of SFC for blend is lesser compared to diesel. 


\subsubsection{MECHANICAL EFFICIENCY}

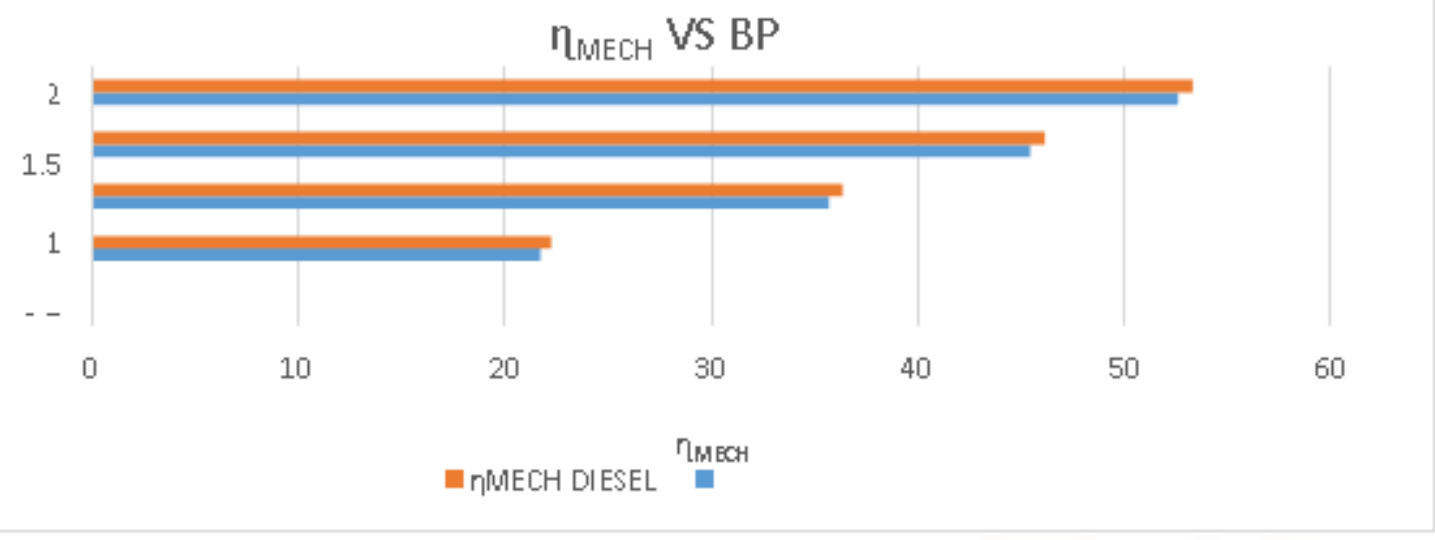

Fig 6.9 Mechanical efficiency vs brake power

From the graph it's clear that the trend of increment in mechanical efficiency for both the fuels are similar. Also the efficiency value of diesel is higher than that of the blend.

\subsubsection{BRAKE THERMAL EFFICIENCY}

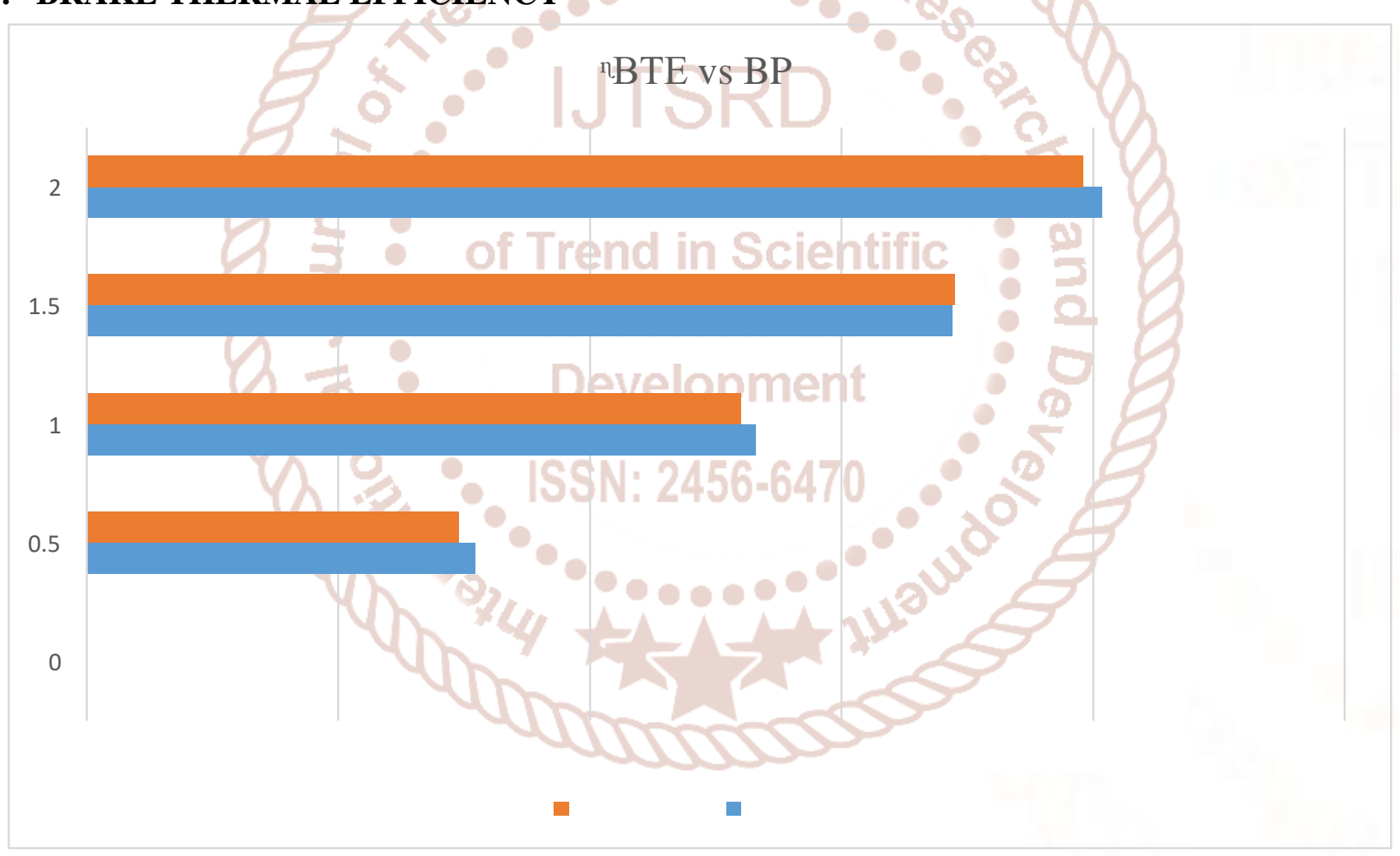

Fig 6.10Brake thermal efficiency vs brake power

The value of brake thermal efficiency of both fuels increases with increase in load value. Also graph shows that the efficiency value of blend is a little higher.

\subsubsection{INDICATED THERMAL EFFICIENCY}

From the graph it's clear that the value of indicated thermal efficiency increases with increase in load value. From the graph we can infer that the value of efficiency for the first load of blend was very much higher than that of diesel. For further increase in value of BP, both the fuels show the same pattern. It's also clear from the graph that the value of efficiency for the blend is higher than that of diesel. 


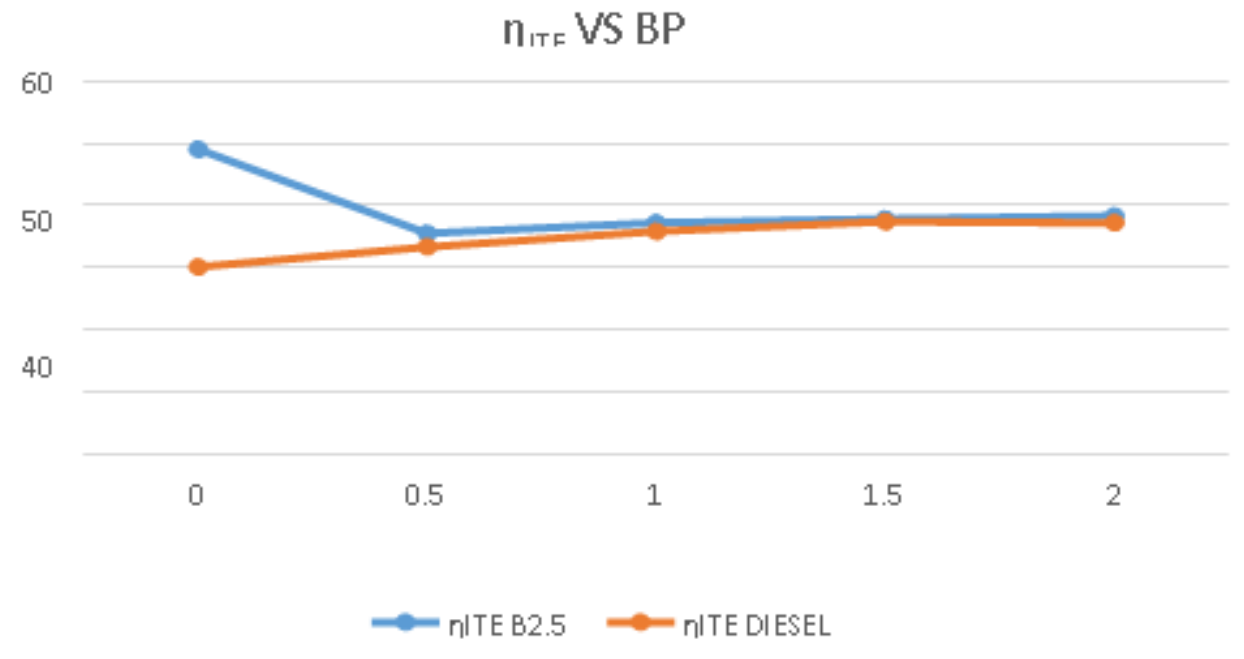

Fig 6.11 Indicated thermal efficiency vs. brake power

\subsubsection{BRAKE MEAN EFFECTIVE PRESSURE}

It is clear from the graph that the value for BMED for both B2.5 and diesel follow similar pattern and similar value as the load increases.

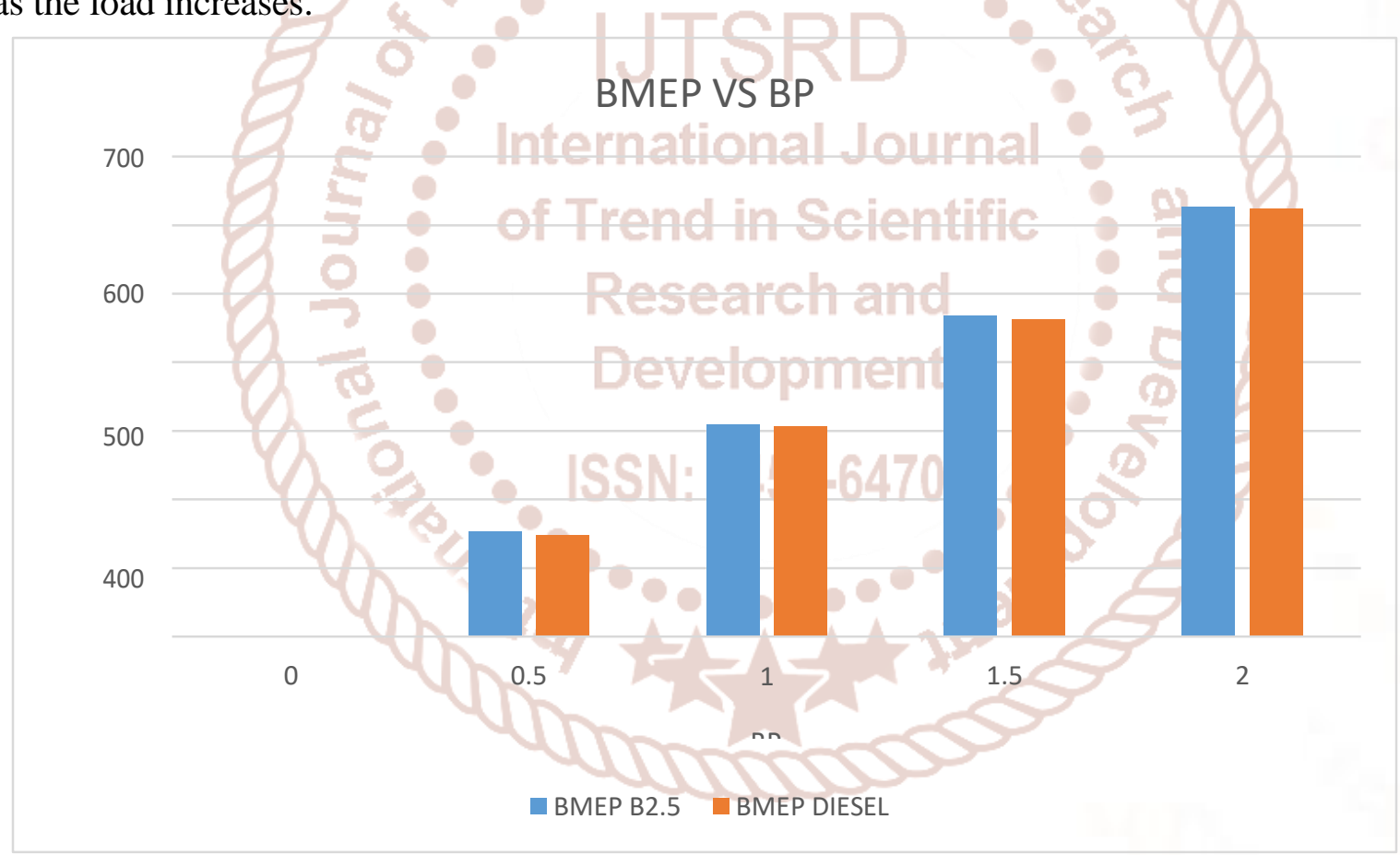

Fig 6.12 Brake mean effective pressure vs. brake power 


\subsubsection{INDICATED MEAN EFFECTIVE PRESSURE}

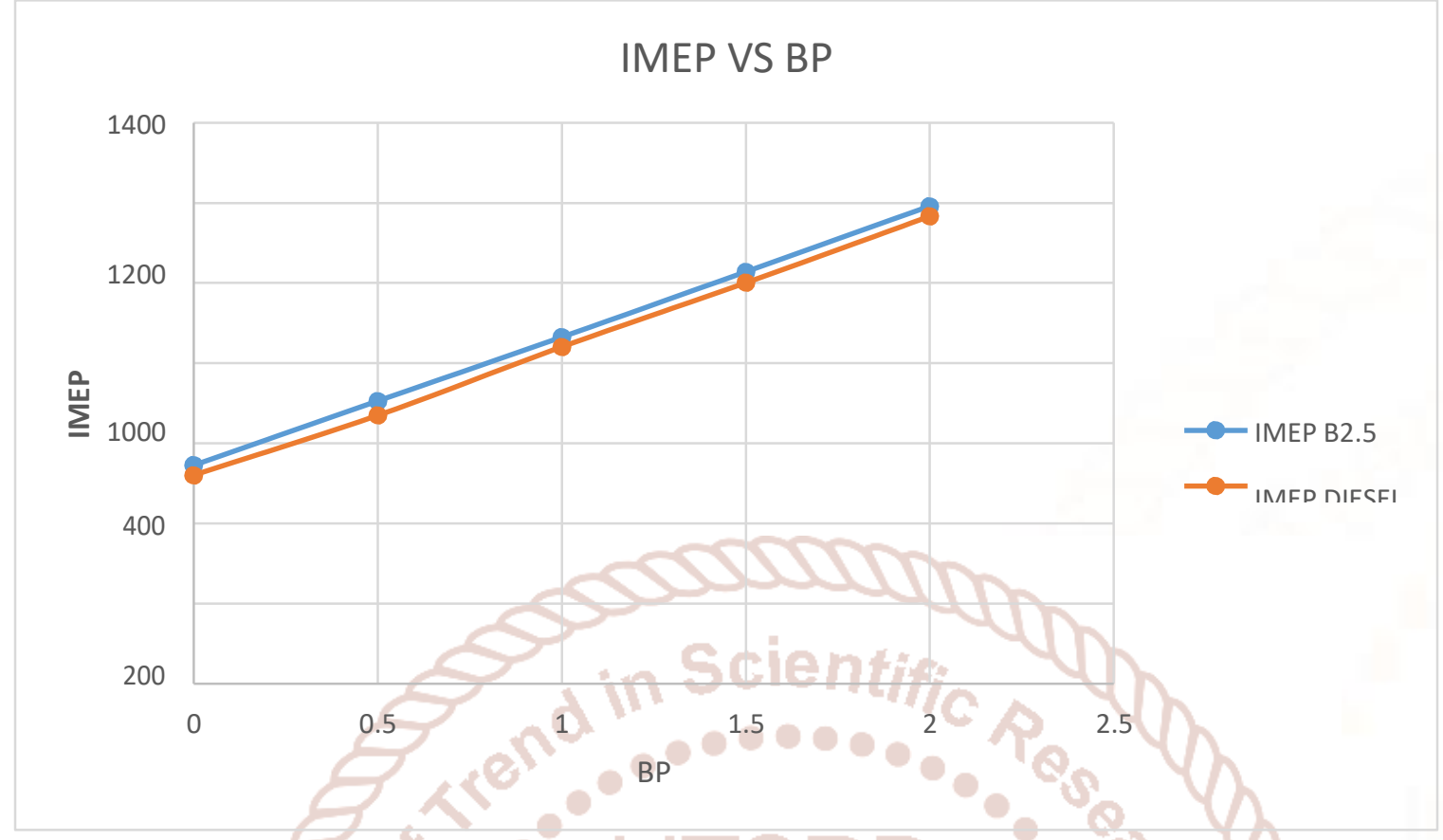

Fig 6.13 Indicated mean effective pressure vs. brake power

From the above graph we can infer IMEP between B2.5 and pure diesel shows steady increase linearly as the load increases. IMEP value of B2.5 is marginally higher than the diesel value.

\subsection{EMISSION CHARACTERSTIC OF B2.5 BLEND}

Table 6.4 Emission characteristic of B2.5 blend

\begin{tabular}{|c|c|c|c|c|c|}
\hline $\begin{array}{c}\text { BP } \\
\text { KW }\end{array}$ & CO & CO2 & HC & O2 & NOX \\
\hline 0 & 0.032 & 1.04 & $56-67 / 0$ & 18.66 & 0319 \\
\hline 0.5 & 0.030 & 0.98 & 10 & 18.77 & 0400 \\
\hline 1 & 0.029 & 1.29 & 12 & 18.23 & 0666 \\
\hline 1.5 & 0.027 & 1.11 & 13 & 18.09 & 0917 \\
\hline 2 & 0.32 & 1.77 & 14 & 17.23 & 01303 \\
\hline
\end{tabular}

\subsection{EMISSION CHARACTERSTIC OF DIESEL}

Table 6.5 Emission characteristic of diesel

\begin{tabular}{|c|c|c|c|c|c|}
\hline $\begin{array}{c}\text { BP } \\
\text { KW }\end{array}$ & $\begin{array}{c}\mathbf{C O} \\
\mathbf{\%}\end{array}$ & $\begin{array}{c}\mathbf{C O 2} \\
\mathbf{\%}\end{array}$ & $\begin{array}{c}\mathbf{H C} \\
\mathbf{p p m}\end{array}$ & $\begin{array}{c}\mathbf{\text { O2 }} \\
\mathbf{\%}\end{array}$ & $\begin{array}{c}\text { NOX } \\
\mathbf{P p m}\end{array}$ \\
\hline 0 & 0.023 & 1.65 & 15 & 17.9 & 800 \\
\hline 0.5 & 0.012 & 1.09 & 19 & 18 & 900 \\
\hline 1 & 0.011 & 1.12 & 21 & 18.75 & 990 \\
\hline 1.5 & 0.013 & 0.9 & 23 & 18.6 & 1070 \\
\hline 2 & 0.010 & 1 & 27 & 18.48 & 1390 \\
\hline
\end{tabular}




\subsection{EMISSION CHARACTERSTIC OF B5 BLEND}

Table 6.5 Emission characteristic of B5 blend

\begin{tabular}{|c|c|c|c|c|c|}
\hline BP & $\begin{array}{c}\mathbf{C O} \\
\mathbf{\%}\end{array}$ & $\begin{array}{c}\mathbf{C O 2} \\
\mathbf{\%}\end{array}$ & $\begin{array}{c}\text { Hc } \\
\mathbf{p p m}\end{array}$ & $\begin{array}{c}\mathbf{O 2} \\
\mathbf{\%}\end{array}$ & $\begin{array}{c}\text { NOX } \\
\mathbf{P p m}\end{array}$ \\
\hline 0 & 0.03 & 1.12 & 13 & 17.99 & 0704 \\
\hline 0.5 & 0.016 & 1.22 & 17 & 18.61 & 0509 \\
\hline 1 & 0.015 & 1.14 & 20 & 18.54 & 0589 \\
\hline 1.5 & 0.013 & 1.36 & 21 & 18.25 & 0954 \\
\hline 2 & 0.012 & 1.85 & 27 & 17.72 & 1228 \\
\hline
\end{tabular}

\subsection{COMPARISON OF EMISSION CHARACTERISTICS OF DIESEL WITH B2.5 AND B5 BLENDS}

\subsubsection{Carbon monoxide}

Carbon monoxide is emitted as a result of incomplete combustion of carbon and oxygen under high temperature inside the cylinder. We can infer that B2.5 produce more $\mathrm{CO}$ compared to other two, whereas B5 blend have similar pattern like of diesel but in a slight higher scale.

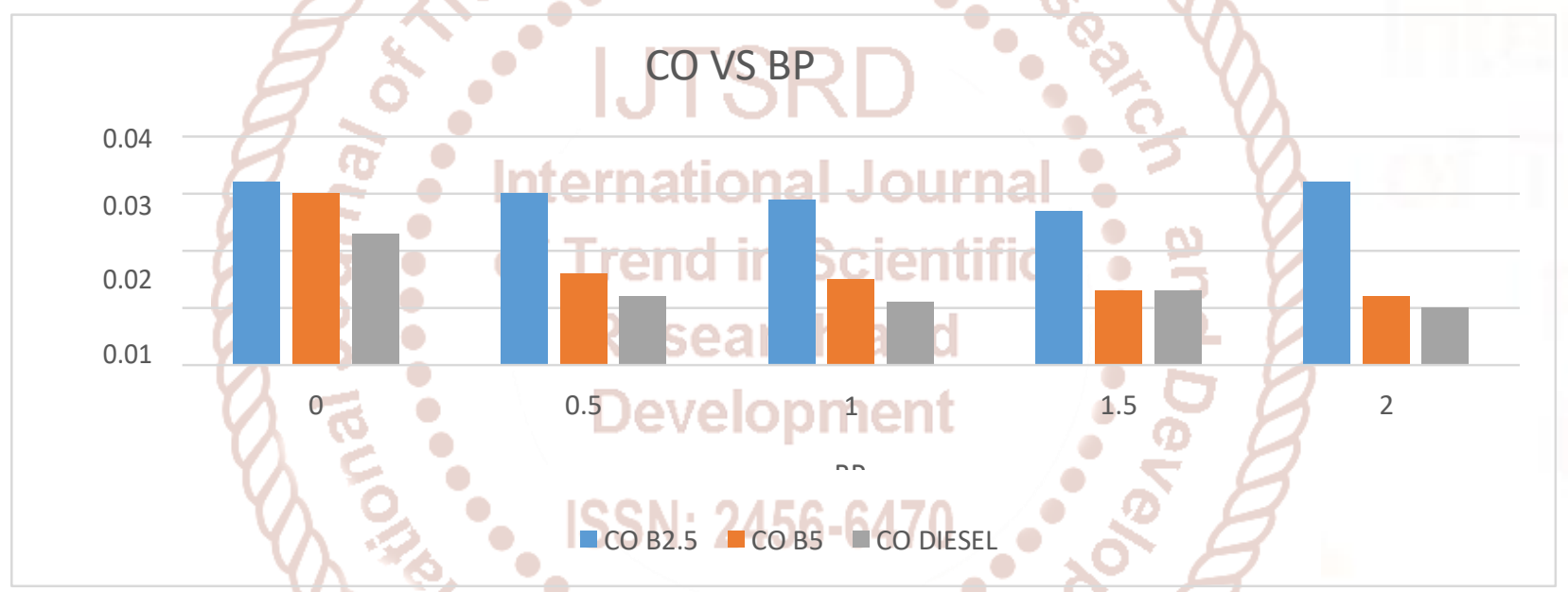

\subsubsection{Carbon dioxide:}

Carbon dioxide comes as exhaust as a result of complete combustion of carbon particles in the fuel and the combustion of CO inside the cylinder. For all the three; diesel, B2.5 AND B5 the pattern for the emission $\mathrm{CO} 2$ is similar but the blends tend to show higher rate of emission compared to diesel, where B2.5 show more similar to the diesel. 


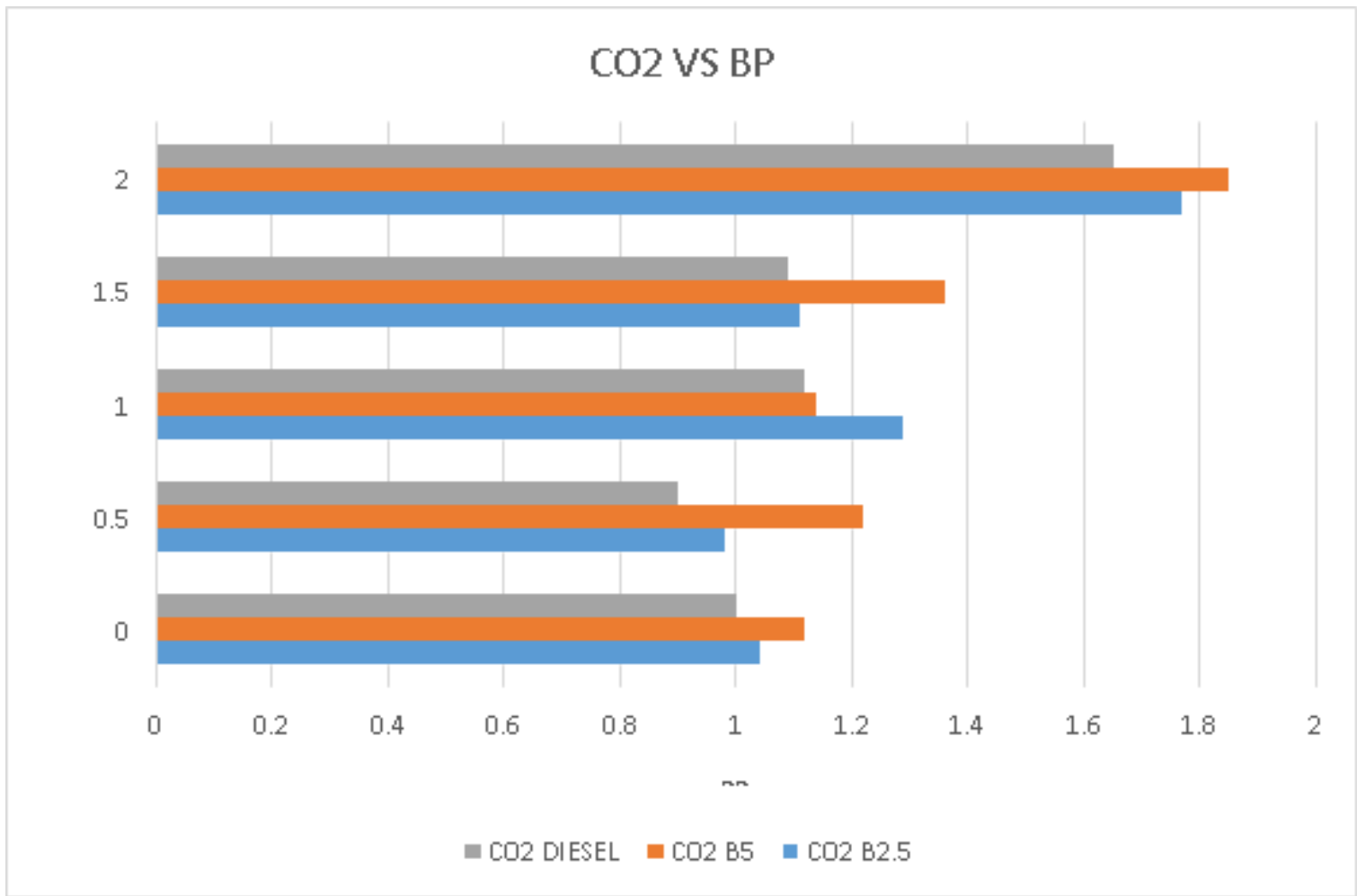

Fig 6.15 Carbon dioxide vs. brake power

\subsubsection{Hydrocarbon (HC):}

Exhaust gases leaving the combustion chamber of an IC engine contains up to $100 \mathrm{ppm}$ of hydrocarbon. These consist of small non equilibrium which is formed when large fuel molecules break up during the combustion reaction. It is often convenient to treat these molecules as if they contained carbon atom. It is seen that $\mathrm{HC}$ emissions increases up to a certain load then decreases for diesel. For both blends it shows increasing trend as the load increases. Under lower load conditions emission in case of diesel is more than that of B2.5 but at higher load.

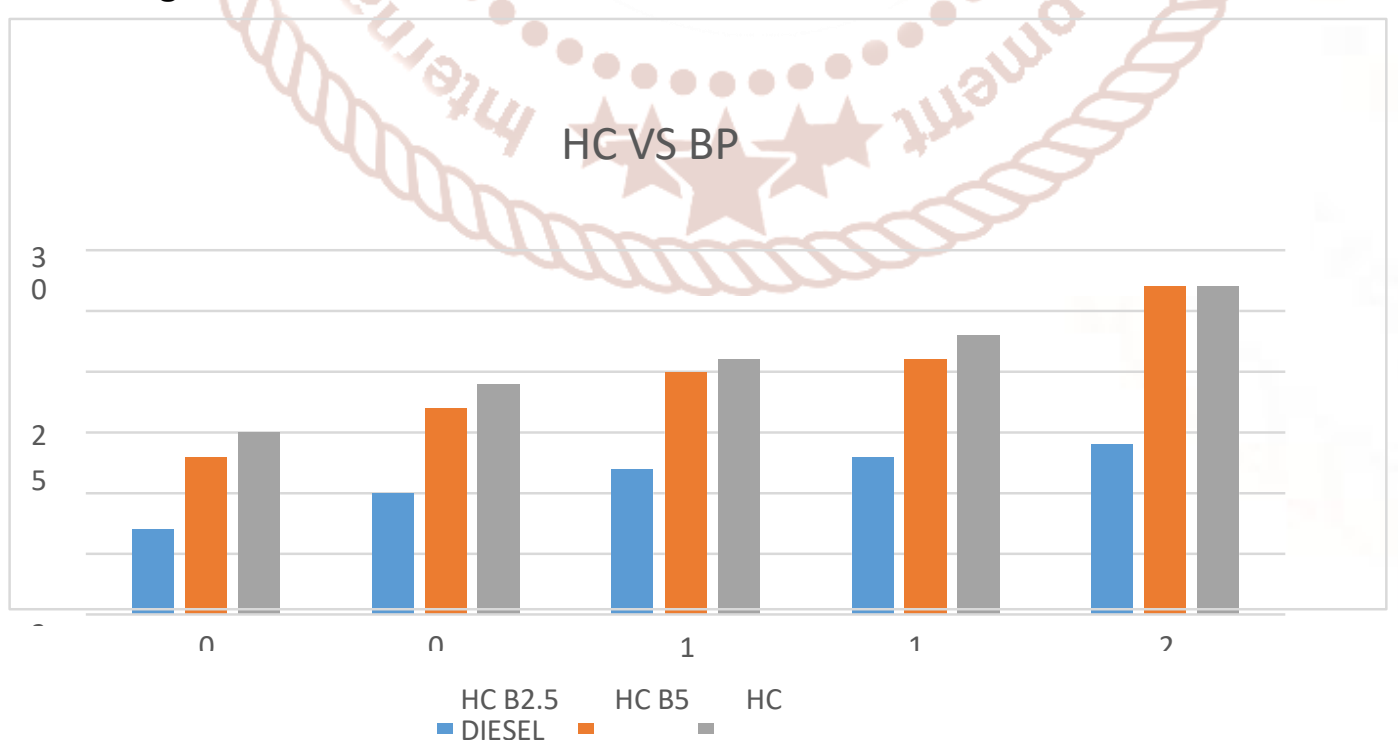

Fig 6.16 Hydrocarbon vs. brake power

Conditions the B5 give more $\mathrm{HC}$ emissions than diesel which is shown in graph above 


\subsubsection{Oxygen (02):}

Oxygen emission shows irregular variation with load. The emission of $\mathrm{O} 2$ for diesel is lower for first 2 loads where as it is higher for the consequent higher loads. From the graph it's clear that the blend B2.5 shows the highest value for $0 \mathrm{~kW}$ BP while it is lowest for $2 \mathrm{~kW}$ BP. Also the value of 02 emission shows lowest value for the minimal and maximum values of BP while they show increasing values for the rest. It is clear that the $\mathrm{O} 2$ emission shows irregular variation for different values of BP.

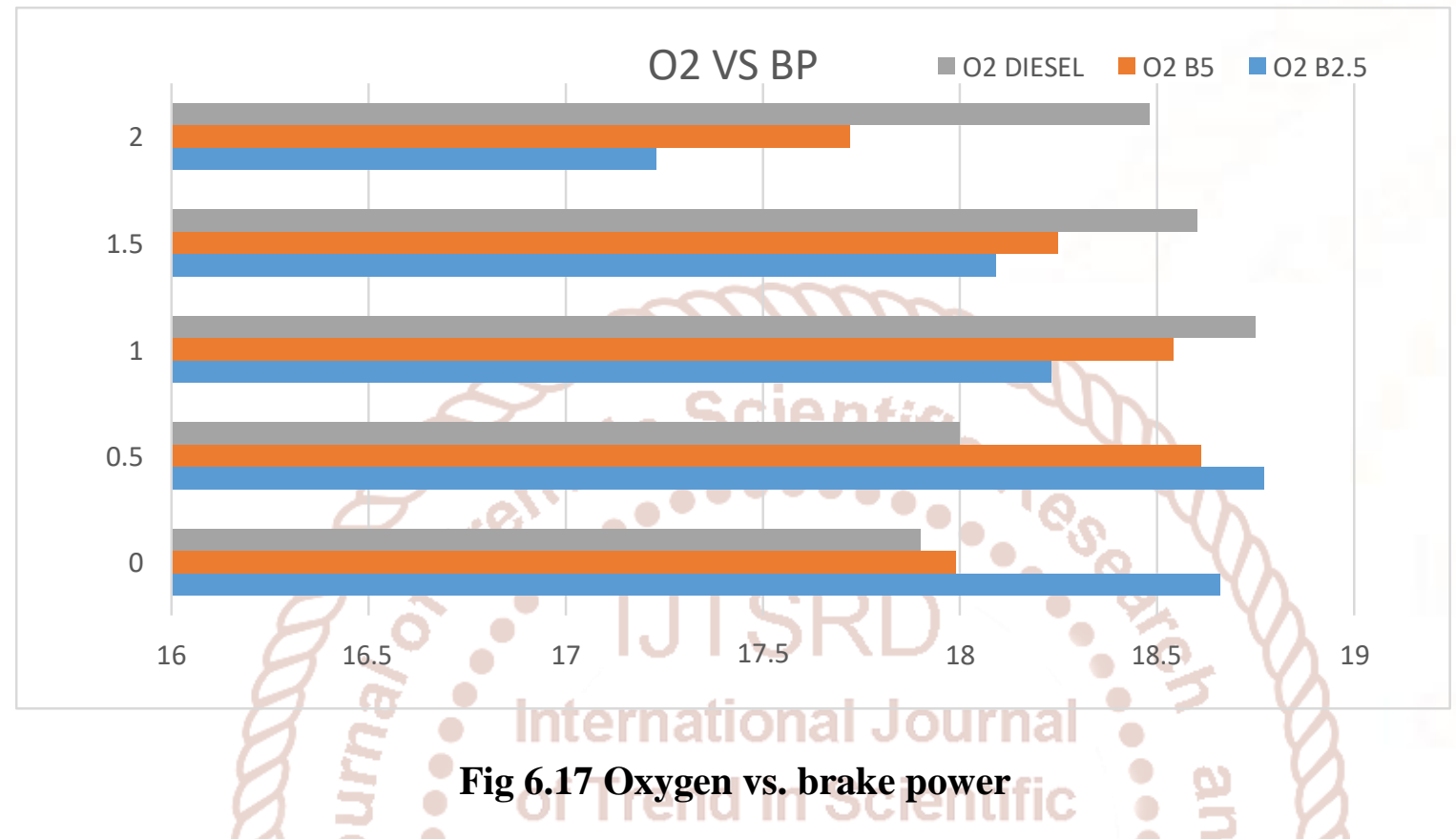

\subsubsection{Nitrogen oxide $\left(\mathrm{NO}_{\mathbf{x}}\right)$ :}

Exhaust gases of an engine can have up to $2000 \mathrm{ppm}$ of oxides of nitrogen. Most of this exhaust contains nitrogen oxide (NO) with small amount of dioxide. These/all come under $\mathrm{NO}_{\mathrm{x}}, \mathrm{x}$ representing some suitable number. $\mathrm{NO}_{\mathrm{x}}$ is very undesirable as it has many adverse effect on the environment. With increase in load NOx emission increases for diesel where both the blends show slight decrease in emission and gradually increase as diesel.

\section{CONCLUSION}

The current project dealt with the extraction of Pyrolysed oil from HDPE and analysing its performance and emission characteristics once distilled. Diesel was kept as standard and the comparison was made. The raw fuel obtained after pyrolysis was distilled to derive the pure pyrolysis oil. Two blends namely B5 and B2.5 were prepared by blending it with diesel.

The flash and fire points of the Pyrolysed oil was tested. The flash and fire points of the oil prepared was less than $37.8^{\circ} \mathrm{C}$ which makes the fuel under the category of flammable fuels. The next series of tests conducted were the performance analysis. The SFC values of both blends were little less than that of diesel but shown similar variation with respect to
BP. The mechanical efficiencies of the 2 blends were lower than that of diesel even though they shown similar variations with BP. The brake thermal efficiencies of both blends were higher than that of diesel and shows similar variations with respect to BP. The indicated thermal efficiencies of both blends were a little higher and shows similar values with respect to diesel. The brake mean effective pressure of both blends were having similar variations with respect to BP value. The indicated mean effective pressure of the prepared blends were higher than that of diesel.

The Emission characteristics were checked once the performance characteristics were analysed. The $\mathrm{CO}$ emission of both the blends were higher than that of diesel. The $\mathrm{CO} 2$ emissions of both the blends were 
higher than that of diesel. The hydrocarbon emission of both blends were lower when compared with that of diesel. The $\mathrm{O} 2$ emission of both blends shown irregular variations when compared with that of diesel i.e. from 0 to $0.5 \mathrm{~kW}$ BP the $\mathrm{O} 2$ emissions were higher and for the remaining $\mathrm{BP}$ values the $\mathrm{O} 2$ emission of blends were lower when compared to diesel. When analysing NOx emission the blends shown lower values compared to diesel. Since the efficiency values are desirable and emission characteristics are fluctuating, for the time being the oil derived could be used to run engines by blending with diesel.

From the analysis it was obvious that the blends shown desirable efficiency values but the emission characteristics possessed irregularities. Thus for better emission characteristics, more care should be given while selecting catalysts and providing experimental conditions. This could enhance the emission characteristics of the Pyrolysed oil. Once the emission characteristics are improved this fuel could be used for running diesel engines.

\section{REFERENCES}

1. Dr. Shinde 'Conversion of waste plastic into resources'- International Journal on Innovation in Engineering and Technology- Volume 6 issue 3 February 2016

2. Vijaykumar B, Chanashetty and B M Patil, 'Fuel from Plastic Waste' International Journal on Emerging Technologies (Special Issue on NCRIET- 2015)

3. Mohamed M Garib Alla, Ahmed I Ahmed, Babiker K Abdalla, 'Conversion of Plastic waste into liquid fuel'-International Journal of Technical Research and Applications -Volume 2, Issue 3 (May-June 2014).

4. Coulson \& Richardson's. 'Chemical engineering design textbook'- Volume 6. [5]. P Baggio'Experimental \& Modeling Analysis of a batch gasification', 'Energy conversion \& management 2009'.

5. Merve Sogoncioglu - 'Comparative study on Waste Plastic Pyrolysis liquid products quantity \&energy recovery potential $2017^{\prime}$.

6. Thallada Bhaskar - 'Pyrolysis of waste plastic using CACO3', 'Progress in rubber, plastic \& recycling technology Volume- 20, 2004'.

7. P Senthil Kumar - 'Conversion of waste plastic into low emissive hydrocarbon fuels through catalytic deploymerization in a new laboratory scale batch reactor', International Journal of Energy environment engineering Volume- 8, 2017. 